\title{
A proposed etiopathology of persistent dysfunctions emerging from use and discontinuation of 5-alpha reductase inhibitors: sequelae of drug-mediated microvasculopathy
}

\author{
Mark Montaigne ${ }^{1}$
}
${ }^{1}$ Pseudonym. Independent researcher and former user of finasteride, United States Email - etiopathology@fastmail.com
DOI: $10.31219 /$ osf.io/86cnm




\section{Summary}

\section{A proposed explanation of lasting dysfunctions after discontinuing use of finasteride or dutasteride}

Men who previously took finasteride and dutasteride have reported sexual dysfunction, anxiety, cognitive problems and other dysfunctions which have continued long after stopping the drug. This paper proposes an explanation for how these dysfunctions may develop. Studies have linked finasteride and dutasteride treatment to changes in penile tissue including reduced size, muscle loss and increased connective tissue, as well as changes to vascular structure and neural signaling pathways supporting erectile function. In some men, perhaps especially younger men, finasteride or dutasteride may stress small blood vessels in penile tissue, reducing the supply of oxygen. The tissue attempts to restore blood flow, but the process may turn pathological, setting off a vicious cycle of vascular deterioration, tissue damage and inflammation. This local progression might develop into a broader inflammatory condition, posing a risk of injury to other structures and systems regulating psychological well-being, thought, sleep, vision and hearing. In this hypothesis, all dysfunctions would arise from tissue injuries in supporting structures and organs. Similar to stroke outcomes, these dysfunctions are variable in nature, severity and course over time. (See also Figures from p. 33 \& Disclaimer on p. 24.)

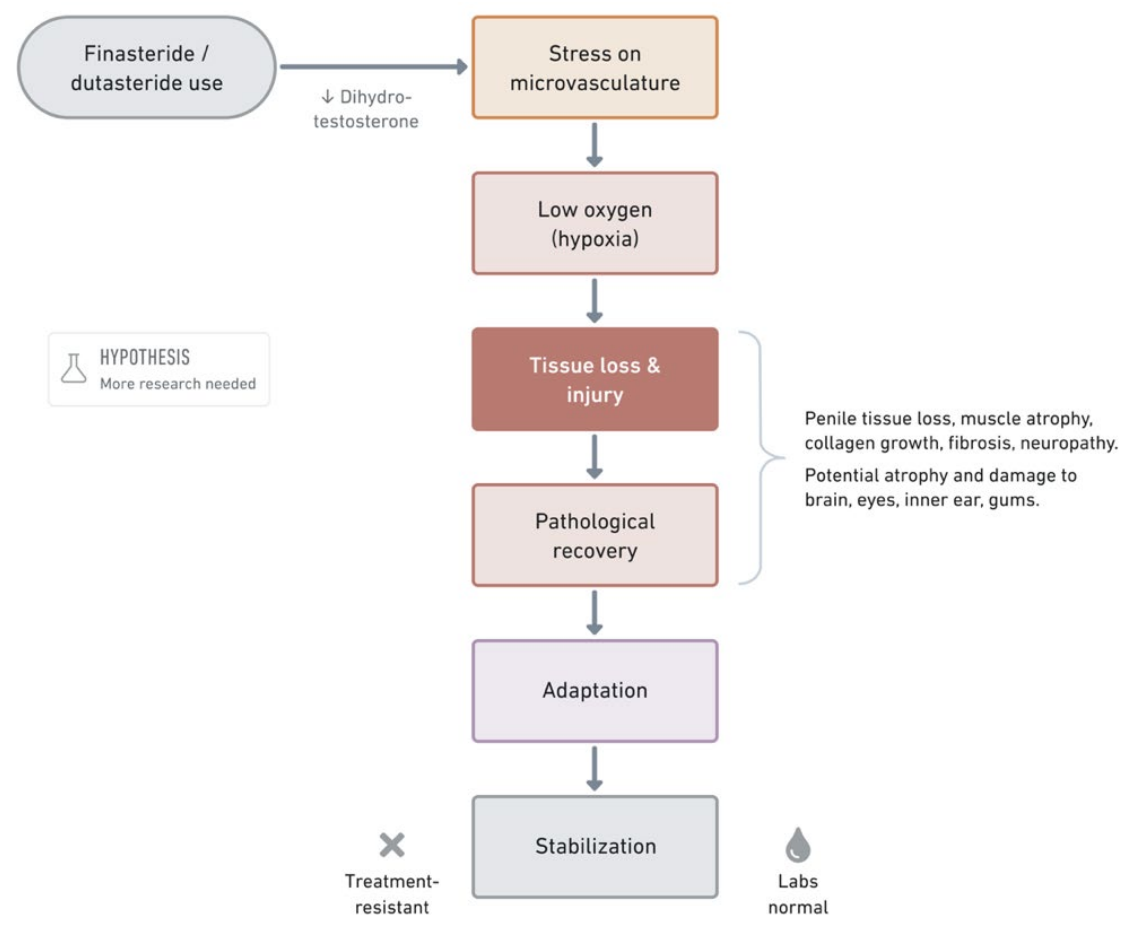




\begin{abstract}
Persistent dysfunctions emerging from use and discontinuation of 5-alpha reductase inhibitors (5ARIs) may be explained as the aftermath of a pathological response to microvasculopathy. Focusing on sexual dysfunction, the most common class of symptoms: 5ARIs' inhibition of angiogenesis leads to stress on penile microvasculature, depriving the tissue of blood supply and oxygen. These hypoxic conditions lead to tissue injury and atrophy, triggering a pathological recovery that further alters penile tissue, including smooth muscle loss, fibrosis, damage to vascular architecture and impairment of neural pathways supporting arousal and erectile function. This damaging cascade may result in severe and lasting sexual dysfunction. Neuropsychiatric, cognitive, sensory and sleep dysfunctions emerging from 5ARI treatment may similarly be explained as pathological responses to microvasculopathy in supporting structures, particularly those in the limbic system. Systemic spread is proposed to arise from a vicious cycle of tissue injury, oxidative stress and proinflammatory activity which spreads via the vascular network, leading to systemic endothelial dysfunction. The latter may in turn set off a damaging cascade in other organs and tissues. Risks of developing lasting dysfunctions may arise from 5ARI-mediated disruptions of vascular tone, angiogenesis and neoangiogenesis. Pharmacovigilance data, animal studies and human studies provide converging evidence for the proposed etiopathology. It is, moreover, consistent with variable presentation and severity of symptoms; irreversibility; typically normal results of clinical lab tests; and resistance to treatment.
\end{abstract}




\section{Introduction}

In the last decade, there has emerged a cottage industry of physicians and researchers advancing psychosocial explanations of persistent dysfunctions after discontinuation of 5-alpha reductase inhibitors (PD-5ARI) ${ }^{1-8}$ A conference abstract hints at paranormal phenomena with the title: "Post-Finasteride Syndrome: Real or Imagined?"9 Three papers from leading lights in urology—strikingly similar in their design, findings and conclusions - have sown doubts about the validity of adverse event (AE) reports. ${ }^{1-3}$ Doctors and researchers have ventured the following explanations for reports of PD-5ARI: nocebo effect, psychogenic erectile dysfunction, distress and psychopathology associated with hair loss, advocacy group efforts, media coverage, social media use, mass psychogenic illness, ${ }^{4}$ false reports by dissatisfied patients and litigation interests. ${ }^{5}$ One author disclosed he was retained by Merck for its Propecia litigation defense, ${ }^{2}$ while others had prior involvement with the drug maker related to finasteride. ${ }^{3,8}$

My own body and functioning changed drastically after taking and discontinuing finasteride. For nearly a decade, my libido has been at zero. My sexual anatomy and physiology are damaged and incapacitated. The situation has not improved since stabilizing after an initial acute phase. From this perspective, the response from luminaries of urology and dermatology looks like a guild closing ranks to protect its interests. ${ }^{10}$ Considerable resources have gone to deflecting drug safety signals by blaming patients in clinical jargon. The medical establishment received notice of this iatrogenic disease from heretics within their own ranks more than a decade ago, ${ }^{11,12}$ yet doctors remain largely in denial.

Integrating research, $\mathrm{AE}$ data, and indeed my own experience, I will propose an etiopathology for PD-5ARI — one which is classically biomedical and recognizable as a variant of known disorders.

\section{Overview of the hypothesis}

The hypothesis emerged from consideration of evidence linking use of 5-alpha reductase inhibitors (5ARIs) to alterations of penile anatomy and physiology in animals and humans. Among younger men taking finasteride for androgenetic alopecia, sexual AEs were the largest cluster among those reported to FDA from 2018 to 2020 (Table 1; 
Appendix: Methodological note on the use of AE data). AEs range from the broad terms Erectile Dysfunction and Sexual Dysfunction to specific abnormalities of the male reproductive system (Tables $2 \mathrm{~A} \& 2 \mathrm{~B}$ ). AEs affecting the penis include Genital Hypoaesthesia (numbness), Penile Size Reduced, Genital Atrophy, Penile Curvature and Peyronie's Disease. A recent pharmacovigilance analysis found a disproportionate signal in reports of penile curvature and Peyronie's disease for finasteride compared to 9 other drugs. ${ }^{13}$ Penile alterations are not associated with depression, anxiety or Internet use. ${ }^{14,15}$ This class of AEs therefore offers a potential foothold to differentiate PD-5ARI from depression and other reductionist interpretations.

It is proposed that PD-5ARI is the aftermath of unsuccessful recoveries from microvasculopathy in structures and systems supporting sexual function, emotion and behavior, cognition, sleep, vision, hearing and orientation (Figure 1A). 5ARIs have been found to inhibit angiogenesis - an effect which may be beneficial for the treatment of prostate conditions in older men. ${ }^{16}$ At the same time, angiogenesis inhibition in normal tissue might stress microvasculature, potentially leading to microvasculopathy and hypoxia. Under hypoxic conditions, tissue damage and cell death may occur ${ }^{17}$ while neoangiogenesis engages to restore microvascular function. Paradoxically, the recovery process may become pathological—not only failing to restore vascular function but resulting in secondary damage and, in some cases, loss of function (Figure 1B). Ischemiareperfusion injury describes such a pathological response, leading to alterations including atrophy, collagen growth, fibrosis and disruption of neural signaling pathways. ${ }^{18,19}$ These outcomes are similar to penile alterations associated with 5ARI treatment and discontinuation cited above. In PD-5ARI, this same progression may also damage tissue in the limbic system and adjacent brain structures, the eye and inner ear. Such damage could lead to temporary or permanent dysfunctions of behavior, affect, cognition, vision, hearing, balance and other functions.

This explanation has analogues in stroke, ischemic kidney diseases and retinopathies which share a similar progression. It is consistent with the very properties of PD-5ARI that have provoked puzzlement and doubt in some observers: variable symptom presentation and course; dysfunctions in multiple systems; resistance to treatment; and typically normal lab results. 
The case for this etiopathology will be developed as follows: 1) 5ARI treatment is associated with penile abnormalities; 2) the course of PD-5ARI has a multiphase character consisting of an acute period, adaptation and stabilization; 3) 5ARIs are angiogenesis inhibitors and are associated with a risk of microvascular events; 4) penile tissue alterations in PD-5ARI are consistent with outcomes of microvasculopathy or ischemiareperfusion injury; therefore, 5) PD-5ARI is hypothesized to emerge from a vicious cycle of vascular deterioration, cell death and inflammation resulting in tissue damage and dysfunction in one or more systems. The remainder of the paper will provisionally explore risk factors and mechanisms, implications for diagnosis and treatment, and future research directions.

\section{ARI treatment has been associated with penile abnormalities}

Several lines of evidence support an association of 5ARI treatment with penile alterations. Animal research has found 5ARI treatment is associated with: reduced size and weight of the penis ${ }^{20,21}$; reduced erectile response; apoptosis ${ }^{22}$; decreased smooth muscle density and increased collagen density in corpus cavernosum ${ }^{20,22,23}$; fibrosis ${ }^{24-26}$; reduced size of sinusoidal spaces in corpus cavernosum ${ }^{20,25}$; reduced expression of endothelial nitric oxide synthase (eNOS) ${ }^{23,27}$; reduced expression of erectile neurotransmitter calcitonin gene-related peptide (CGRP) ${ }^{28}$; and, in a dutasteride study, reduced expression of androgen receptor. ${ }^{26} \mathrm{~A}$ review commented that an animal study's findings "indicate that 5ARIs have a significant pathogenic impact on the penile histo-architecture and attenuate the NOS signaling pathway. ${ }^{29}$ Da Silva et al. attributed morphological changes to depletion of dihydrotestosterone (DHT) in penile tissues and observed: "The possibility of recovering normal penile morphology after discontinuing [finasteride or dutasteride] and whether either of the drugs is associated with a faster or more complete return to a normal penile morphology remains unknown." 20 Two studies investigated whether erectile parameters in dutasteride-treated rats recovered after a washout period. Öztekin et al. found that after 6 weeks of dutasteride treatment followed by a 2-week washout period, certain erectile parameters - including intracavernosal pressure and contractile response in cavernosal smooth muscle - did not recover. ${ }^{30}$ Sung et al. found that persistence of erectile dysfunction depended on duration of treatment: rats receiving 4 weeks of dutasteride 
treatment recovered erectile function after the washout period, but 8 weeks of treatment led to irreversible erectile dysfunction. Penile tissue changes were also noted in treatment groups. The ratio of smooth muscle to collagen in cavernosal tissue remained low after the washout period, while expression of fibrosis-related factors such as TGF- $\beta 1$ and TGF- $\beta 2$ remained elevated. ${ }^{24}$ Selected images of penile alterations emerging from 5ARI treatment have been reproduced in Figures 2-4. ${ }^{20,22,25}$

Human research on penile abnormalities associated with 5ARI treatment is sparse, but bears consistency with the animal research. A study which performed penile ultrasound imaging on men with PD-5ARI found penile vascular abnormalities in $68 \%$ of participants. ${ }^{31}$ The abnormalities were arterial insufficiency, venous leak and peak systolic velocity in a "gray zone" below normal range. A previously-cited pharmacovigilance analysis found a disproportionate signal for reports of penile curvature or Peyronie's disease associated with finasteride. ${ }^{13}$ A pilot study reported abnormal somatosensory evoked potentials of the pudendal nerve in 4 of 16 post-finasteride patients. Three of the 4 patients had no reproducible response to the stimulus. ${ }^{32}$

Two cases of penile alterations associated with finasteride treatment were reported in Argentina. ${ }^{33}$ After discontinuing finasteride, Case 1 began to experience "a 'flaccid but rigid' penile state, less penile length and girth, scrotal shrinking, more visible superficial penile veins, mild flaccid penile pain, mild distal penile curvature to the right, severe post ejaculatory asthenia and less muscle tone and strength." Penile ultrasound imaging showed a plaque in right corpus cavernosum suggesting possible fibrosis, while the penile MRI result was normal. Case 2 had a history of Ewing Sarcoma and testicular cancer followed by unilateral orchiectomy, but had been disease-free for 5 years with no sexual dysfunction prior to the reported changes. After a single dose of finasteride, he reported "severe erectile dysfunction...lack of any morning erections, less penile length and girth...penile hyposensitivity, more visible superficial penile veins, moderate penile, testicular and perineal pain...hypospermia and a 'more watery' semen, less intense orgasms, asthenia and articular and muscular pain..."

AEs reported to the Food \& Drug Administration (FDA) Federal Adverse Events Reporting System (FAERS) are consistent with the animal and human research (Tables 2A $\& 2 B$ ). Filtering criteria were applied to minimize confounding factors (Table $2 \mathrm{~A}$ caption). 
The proportion of genitourinary AEs of finasteride in men $18-40$ was $10.2 \mathrm{x}$ greater than that of a comparable group of men who used minoxidil, another hair loss treatment taken by a similar population. In the subset of AEs affecting the penis and erectile function, the proportion of AEs was 11.2x greater for finasteride compared to minoxidil. These included: Penile Size Reduced, Peyronie's Disease, Male Genital Atrophy and Penile Curvature, as well as the broader terms Erectile Dysfunction and Sexual Dysfunction.

Although researchers have advanced psychogenic explanations of these last two AEs,${ }^{1-8}$ in fact these terms are non-specific as to origin. For exploratory purposes these AEs have been included with penile AEs. Tables 2A and 2B summarize genitourinary AEs of finasteride by subsystem. Figure 5 provides a visual overview of genitourinary AEs of finasteride.

\section{PD-5ARI has a multiphase course}

The course of PD-5ARI has received scant attention in research literature. By the time a man with PD-5ARI sees a clinician, files an AE report or enrolls in a research study, a sequence of events has unfolded. Figure 6 shows a canonical disease course integrating my experience with that of others (systematic evidence is not available; see sources of firsthand reports in Supplement). The four major phases are: injury, pathological recovery, adaptation and stabilization. The figure shows a correspondence with the phases of ischemia-reperfusion injury.

To return to the original, practical question: what could explain that a young man with a healthy, functioning penis begins taking a 5ARI, experiences AEs and, within a few weeks or months after discontinuation, emerges with a collagenous, fibrotic, nonfunctioning penis? The next section lays the foundation by reviewing the basics of angiogenesis as well as angiogenic effects and risks of 5ARI use.

\section{Background on angiogenesis}

Under normal conditions, microvascular tissue is sustained by oxygen, a process in which vascular endothelial growth factor (VEGF) has an important role. ${ }^{34}$ Oxygen levels in tissue fluctuate over time. When oxygen runs low, hypoxia-inducing factor 1a (HIF-1a) is expressed, inducing neoangiogenesis. ${ }^{35,36}$ VEGF is then upregulated, leading to increased 
vascularization and restoring oxygen supply. ${ }^{36,37}$ Ongoing adjustments to expression of angiogenic factors thus allow tissue to remain healthy under fluctuating levels of oxygen. 37,38

Under hypoxic conditions, such as after ischemia, neoangiogenesis may go awry. The recovery process may paradoxically trigger further injuries, resulting in potentially permanent loss of function. This has been described as pathological angiogenesis or ischemia-reperfusion injury. ${ }^{36,39}$ Early in the process, apoptosis occurs. Anti-inflammatory processes may trigger the production of collagen, culminating in fibrosis which can interfere with normal organ function. ${ }^{40}$ In kidney disease this has been described as an acute kidney injury-to-chronic kidney disease transition. ${ }^{41}$

\section{Angiogenic effects and risks associated with 5ARI use}

\section{$\underline{\text { 5ARIs inhibit angiogenesis }}$}

Benign prostatic hyperplasia and prostate cancer have been associated with increased microvascular density and increased expression of VEGF in prostate tissue. ${ }^{42-44}$ 5ARI treatment has been shown to suppress VEGF and HIF-1a in the prostate. ${ }^{16,45,46}$ In an animal model, finasteride treatment also reduced VEGF expression in kidney tissue. ${ }^{47}$

As a drug class, VEGF inhibitors have been associated with thrombotic microangiopathy ${ }^{48-51}$ and arterial thromboembolic events. ${ }^{52}$ Touyz et al. described how VEGF inhibition can lead to an imbalance in vasodilatory and vasoconstricting factors, producing "vascular toxicities." 52 Kuenen et al. linked thromboembolic events under VEGF inhibition to VEGF's role in maintenance and repair of endothelial cells. ${ }^{53}$

\section{$\underline{\text { Association of microvascular events with 5ARI use }}$}

Several lines of evidence indicate microvascular risks of 5ARI treatment. In an epidemiological study, 5ARI use was associated with an elevated risk of venous thromboembolism, with a higher risk for long-term users. ${ }^{54}$ A systematic review of cardiovascular risks of dutasteride in an older population found no increased risk of stroke $^{55}$; however, it included trials with active controls, one of which was finasteride, and a placebo-controlled trial likely to underestimate risk (relatively short duration; $39 \%$ of participants on $2 \%$ or $10 \%$ of the standard dose). Excluding these trials, recalculated RR of 
stroke for dutasteride was higher than placebo at $1.36(1.004,1.845 ; P=0.048)$ (details in Supplement).

A cohort study by Shores et al. explored predictors of stroke risk in 1,032 men of mean age 76.5. The analysis found a nonlinear relationship where DHT levels below or above $50-75 \mathrm{ng} / \mathrm{dL}$ were significantly associated with stroke risk. ${ }^{56}$ This suggests indirectly that 5ARIs' effect of lowering DHT could be a contributor to stroke risk.

The above studies focus on older men, but several case reports concern younger men. Two cases of serious vascular events associated with finasteride treatment were reported in Japan: a 35-year-old male who had been taking finasteride for 6 months was diagnosed with sinus thrombosis and brain hemorrhage; and a 41-year-old male taking finasteride and minoxidil was diagnosed with cerebral infarction. The paper noted other vascular AEs of finasteride recorded by the Japanese regulatory authority: 14 cases of thrombosis, 4 cases of stroke (including the 2 mentioned here), 6 cases of myocardial infarction and 4 cases of other thrombotic diseases. ${ }^{57}$ In Korea, a case of cerebral venous thrombosis (CVT) and retinal hemorrhage was reported in a 25-year-old male taking dutasteride, with the drug seen as a potential cause of CVT ${ }^{58}$ Another case report from Korea described finasteride-induced CVT in a 41-year-old man. ${ }^{59}$

Selected vascular AEs of finasteride and minoxidil in men 18-40 are summarized in Table 3. The proportion of vascular occlusive AEs (involving thrombosis, embolism, occlusion, ischemia or infarction) is $5.8 \mathrm{x}$ greater for finasteride compared to minoxidil (6.5x greater if the ambiguous term Cerebral Disorder is included).

We have reviewed an association of angiogenesis inhibitors with microvascular risks, as well as specific evidence linking 5ARI treatment to microvascular events including stroke. We will next review examples of ischemia-reperfusion injury as analogues of the course and outcomes of PD-5ARI.

\section{Examples of ischemia-reperfusion injuries}

Much of the clinical research on ischemia-reperfusion injury relates to kidney disease, stroke and surgery. Related basic research has delved into its progression at cellular and molecular levels with reference to angiogenesis, neoangiogenesis, 
inflammation, neural signaling and epigenetic changes. This brief review includes research spanning these several levels of explanation.

\section{Ischemia-reperfusion injury in kidney diseases}

An ischemic event in the kidney may cause inflammation and microvasculopathy. The microvasculopathy may in turn result in permanent deterioration of the capillary network and increase the risk of chronic kidney disease. ${ }^{60}$ Following ischemia, microvascular rarefaction and hypoxia can lead to fibrosis, scar formation, and a "vicious progression" towards eventual kidney failure. ${ }^{40,61,62}$ This damaging cascade has been attributed to "inappropriate activation" of HIF which may increase the expression of fibrogenic genes; ${ }^{61}$ and to dysregulation of angiogenic factors as a consequence of hypoxia. ${ }^{63}$ A review on the transition from acute kidney injury to chronic kidney disease (AKI-CKD transition) describes how, in recovering from injury, a subpopulation of tubules stops growing and becomes atrophic. These tubules interfere with normal tissue recovery, leading to profibrotic signaling and capillary disintegration and rarefaction. ${ }^{41}$ Another study in nephrology examined the effect of different lengths of induced ischemia on markers for injury, inflammation and fibrosis. ${ }^{64}$ They noted a "point of no return" time of 35 minutes, beyond which markers for inflammation, injury and partially for fibrosis remained elevated through 5 weeks after the ischemic event. Persistent cell death and atrophy were observed in the groups with ischemia of 35 minutes or greater, but not the shorter-duration ischemia groups.

The comparison with kidney disease is not merely theoretical. As mentioned earlier, 5ARI treatment has been shown to suppress VEGF in kidneys. ${ }^{47}$ Animal research has shown that $5 \mathrm{ARI}$ treatment can result in morphological and functional damage to kidneys. ${ }^{65}$ Baig et al. found Type I and Type III collagen were increased, respectively, in the interstitial cortical region and glomerulus of finasteride-treated rats, with the latter leading to glomerulosclerosis. The overall percentage of collagen in sampled kidney tissue of finasteride-treated rats was more than double that of controls. Baig et al. also found: reduced expression of androgen receptor in the cortical region; reduced expression of intercellular junctional proteins; increased ratio of apoptotic to proliferative nuclei; and proliferation of IL-6 and lymphocyte markers in kidney tissue. ${ }^{66}$ This study's observations 
of tubulointerstitial fibrosis and tubular atrophy recall findings of fibrosis and atrophy of penile tissue linked to finasteride treatment discussed earlier.

\section{Ischemia-reperfusion injury in stroke}

The progression of ischemic stroke parallels that of hypoxic kidney injury. Nour et al. described a paradoxical process in which a post-ischemic recovery process may lead to further damage. Following ischemia, activation of the immune system and complement system may cause cell death, setting off a proinflammatory cascade. Another contributor to injury is the production of reactive oxygen species (ROS) via inducible nitric oxide synthase (iNOS), leading to necrosis and apoptosis. These injuries result in "a change in the nature of the vascular system as a whole." Dysfunction in cellular metabolism induces inflammation of endothelial cells and increased vascular permeability. Importantly, Nour et al. point out: "this injury lasts beyond the period of ischemia." Ischemia-reperfusion injury alters DNA and protein expression in the blood-brain barrier (BBB), leading to oxidative cell damage. Increased vascular permeability of BBB may lead to edema, interfering with reperfusion. The degree of permeability of BBB has been correlated with severity of clinical outcomes of stroke. Reperfusion injury may, moreover, affect autoregulation of cerebral blood flow. ${ }^{39}$

\section{Ischemia-reperfusion injury as a model for PD-5ARI progression}

Emergence of sexual dysfunction

The background has been established to trace how penile alterations could emerge and progress from 5ARI treatment and discontinuation. The sequence would begin with stress on microvascular tissue in the penis, creating hypoxic conditions. As in acute kidney injury and stroke, hypoxia may induce capillary rarefaction, ${ }^{67,68}$ apoptosis and necrosis, triggering neoangiogenesis. 5ARI use may disrupt angiogenesis in several ways. First, 5ARI use reduces expression of VEGF, HIF-1a and eNOS, all of which are involved in physiological angiogenesis. Second, discontinuation of 5ARI use might lead to a rebound of these factors - potentially explaining reports of worsening conditions after drug discontinuation. ${ }^{69}$ Finally, a low DHT environment has been associated with proinflammatory activation. ${ }^{70}$ Similar to the "vicious progression" in kidney disease, a 
pathological recovery in penile tissue could produce secondary effects such as tissue atrophy, fibrosis, damage to neural signaling pathways, and consequently erectile dysfunction (Figure 6 \& Figure 1B).

Progression of the autoimmune disease systemic sclerosis (SSc) provides a reference point. In SSc, microangiopathy may produce hypoxic conditions in multiple organs and systems. Attempted neoangiogenesis fails because of an imbalance of pro- and anti-angiogenic factors. ${ }^{71}$ A pathological tissue recovery process ensues, resulting in loss of microvasculature, an impaired vascular repair mechanism and fibrosis. ${ }^{72-74} 80$ to $90 \%$ of men with SSc have erectile dysfunction. In these men, blood flow in penile arteries is inhibited due to corporal fibrosis and myointimal proliferation. ${ }^{75}$

\section{Emergence of other areas of dysfunction}

It is proposed that the neuropsychiatric, cognitive, sleep and sensory dysfunctions of PD-5ARI may be a consequence of 5ARI-related injuries in supporting structures and organs. Oral 5ARIs are systemic, so it is plausible that microvascular effects observed in prostate or kidneys might affect other tissues, organs and functions. The mechanism for systemic progression (elaborated in more detail in the following section) is proposed as a local vicious cycle culminating in proinflammatory activity which spreads via the vascular network, resulting in systemic endothelial dysfunction (Figure 1B).

Table 4 indicates anatomical structures supporting functions which are impaired in PD-5ARI. Neuropsychiatric, cognitive and sleep dysfunctions show a correspondence with functions of the limbic system - for example, the medial preoptic area is a crucial site mediating male sexual behavior. ${ }^{76}$ Regarding cognitive dysfunction, Diviccaro et al. have shown alterations to hippocampal neurogenesis 30 days after withdrawal from finasteride in an animal model. ${ }^{77}$

Regarding ocular adverse effects, systemic finasteride is associated with decreased vision and tear film abnormalities. It has a probable association with intraoperative floppy iris syndrome and conditional association with retinal vascular accidents. ${ }^{78,79}$ A recent retrospective study of 116 patients found an association of finasteride and meibomian gland dysfunction, as well as conjunctival and corneal abnormalities. ${ }^{80}$ In another study, ophthalmologists reviewed histories of 28 patients of their clinic known to have taken 
finasteride. While acknowledging selection bias, Nguyen et al. reported evidence of visual dysfunction in 25 patients $(89 \%)$, 7 of whom had optic nerve and retinal damage as measured by visual evoked potentials and electroretinogram. ${ }^{81} \mathrm{~A}$ co-author of this research published a letter of concern suggesting ocular adverse effects of finasteride are underrecognized. ${ }^{82}$

A cohort study on dental effects of finasteride found gingivo-periodontal lesions in $21 \%$ of 84 patients. ${ }^{83}$ In the present author's experience and in reports of others, rapid and irreversible gum recession may occur during the erratic recovery phase after discontinuation of 5ARI use.

\section{$\underline{\text { Parallels with stroke }}$}

A comparison of stroke and PD-5ARI shows a striking parallelism (Table 5). In both conditions, there is considerable variability of course and outcomes. Varying outcomes of stroke are unsurprising because we have a mature understanding of the condition. ${ }^{84} \mathrm{~A}$ stroke rehabilitation clinic advises: "Every stroke recovery prognosis is different because every stroke is different." ${ }^{, 85}$ As for the variability of PD-5ARI, Figure 7 represents a wide range of possible courses and outcomes across four areas of dysfunction. As in stroke, this variability becomes more plausible as a consequence of variable localization, severity, progression and outcomes of drug-mediated tissue injuries.

Figure 8 contrasts a symptom view with a system view of the disease. In the former view, symptoms are considered piecemeal. This limited frame of reference has led to a stalemate over whether there is any disease entity to speak of at all. ${ }^{3,7}$ Conversely, in the system view, symptoms may be understood as the aftermath of a complex cascade following tissue injuries - one in which variability is multiplied at each stage (Figure 1B). In this account, variability need not prompt suspicions of malingering or factitious disorder; it is, rather, a natural consequence of the disease process.

\section{Risk factors and potential mechanisms}

Risk factors for developing PD-5ARI are unknown. Anecdotally, the disorder seems more common in younger men, with some men reporting severe, complex reactions after as little as 1 dose. ${ }^{33}$ This section will review candidate mechanisms and risk factors: 
1) mediation of angiogenesis by androgen levels and age; 2) effects of 5ARIs on angiogenic factors; and 3) the progression from a local vicious cycle to a systemic condition.

\section{Androgen mediation of angiogenesis}

Androgens and androgen receptors (AR) have a critical role in maintaining and repairing vascular function in health and disease. ${ }^{86-88}$ Using dermal fibroblasts from young and old men, Lecce et al. found DHT treatment resulted in an increase in VEGF expression in tissue of young men, but not that of old men. This difference was found to depend upon the sensitivity of androgen receptor in tissues. ${ }^{89} \mathrm{Ye}$ et al. examined the effect of DHT treatment on endothelial progenitor cells (EPCs). DHT enhanced the angiogenic action of EPCs and differentially upregulated angiogenic genes in EPCs. ${ }^{90}$ DHT has been shown to reduce the inflammatory response in vascular endothelial cells. Low androgen levels are associated with apoptosis of cavernosal endothelial cells. ${ }^{88}$ These findings suggest a low DHT environment could disrupt the angiogenic balance and fail to contain inflammation in vascular tissue.

AR, which mediates beneficial effects of DHT on vascular tone, has been found over- or underexpressed across several studies involving 5ARI treatment. Baig et al. found decreased expression of AR in kidneys of finasteride-treated rats, ${ }^{66}$ while Enatsu et al. found reduced AR expression in the prostate and penis of rats treated with dutasteride compared to controls. ${ }^{26}$ Conversely, a human study found higher expression of AR in prepuce of post-finasteride patients. ${ }^{91}$

\section{Androgen mediation of post-ischemic neoangiogenesis}

Androgens, AR and age also mediate the response to ischemic events. Lam et al. investigated the effects of DHT treatment on a mouse model of hindlimb ischemia. In wild-type, castrated mice (inducing an androgen deficiency), DHT treatment enhanced blood flow recovery after ischemia and increased HIF-1a levels in ischemic tissues. In knockout mice with inactivated AR, DHT treatment did not lead to blood flow recovery and the increase in HIF-1a was attenuated. ${ }^{92} \mathrm{~A}$ subsequent study identified age-related differences in vasculogenesis after ischemia, including that HIF-1a was increased in young 
but not old mice. ${ }^{93}$ Shafighi et al. found that in male human umbilical vein endothelial cells, DHT increased HIF-1a. In a second experiment, mice with an induced androgen deficiency (via orchiectomy) were given a skin flap operation. Compared to controls, this group had lower VEGF, lower perfusion and lower survival of tissue compared to controls. The authors concluded that androgen-mediated HIF-1a expression results in increased expression of VEGF and perfusion. ${ }^{94}$

A model of cerebral ischemia in castrated mice found that mice treated with $0.5 \mathrm{mg}$ DHT had smaller infarct volumes compared to untreated controls. A higher dose of $1.5 \mathrm{mg}$ DHT led to a worse outcome than controls. All DHT effects were blocked by an androgen receptor antagonist, suggesting that DHT mediation of angiogenesis requires the AR pathway. ${ }^{95}$

Aging has been associated with impairment of angiogenesis. ${ }^{96}$ In elderly patients, outcomes from ischemia and infarction tend to be worse because of age-related impairments to angiogenesis. The HIF-1a response to ischemia is mediated by age, with older mice showing reduced HIF-1a expression under hypoxic conditions. ${ }^{38}$ Bosch-Marce et al. compared ischemia in mice with a partial HIF-1a deficiency (HET) to wild type (WT). After ischemia in 2-month old mice, expression of HIF-1a was lower in HET compared to WT, but this difference was not observed in 20-month old mice, where HIF1a expression was relatively low in both groups. ${ }^{97}$

The evidence reviewed suggests angiogenesis is generally more responsive, and potentially more sensitive to androgen mediation, at younger ages. HIF-1a expression is mediated by DHT. 5ARIs inhibit DHT levels, and their effect of angiogenesis inhibition is considered therapeutic for prostate conditions, typically in older men. ${ }^{45,46}$ There is a plausible basis to hypothesize that 5ARI treatment may differentially disrupt angiogenesis in young men because of greater androgen sensitivity. This disruption could create the conditions for microvasculopathy in the first place, and also impair the post-ischemic response. Moreover, an increase in DHT after discontinuation could cause a rebound in angiogenic factors, potentially further disrupting recovery. 


\section{Effects of 5ARIs on angiogenic factors}

This section provides background on VEGF, then reviews additional evidence linking 5ARI use to altered levels of angiogenic factors. VEGF increases microvascular permeability, and has been implicated in microvascular events leading to organ dysfunction. VEGF activation can cause a loss of integrity of endothelial cell junctions ${ }^{98}$ and lead to the formation of fenestrations ${ }^{98}$ whereby a segment of a single artery divides into at least two channels. ${ }^{99}$ Fenestrations may contribute to loss of glomerular function in kidneys. ${ }^{98}$ In diabetes, systemic endothelial dysfunction induces hypoxia and upregulation of VEGF in the retina. VEGF upregulation in turn contributes to vessel proliferation, leakage and neovascularization, disrupting vision. ${ }^{98}$ Circumstantially, these outcomes recall penile vascular abnormalities observed in post-5ARI patients such as arterial insufficiency, venous leak and marginal peak systolic velocity. As noted previously, 5ARI treatment is associated with reduced expression of VEGF in the prostate and kidneys. ${ }^{45,47}$ Discontinuation of 5ARI use could therefore prompt a rebound of VEGF levels, disrupting neoangiogenesis already underway.

Animal studies have demonstrated effects of 5ARI treatment on expression of NOS isoforms in rat corpus cavernosum. eNOS expression was reduced in corpus cavernosum of finasteride-treated rats. ${ }^{22}$ Two recent animal studies found differing effects of dutasteride on expression of NOS isoforms in rat corpus cavernosum. ${ }^{22,24}$ A review described the critical role of nitric oxide (NO) production and sensitivity in maintaining vascular homeostasis, and suggested that impairment of NO signaling has a "central link" to endothelial dysfunction. The resulting imbalance in vascular homeostasis has a proinflammatory effect on blood vessel walls, and is linked to dysfunctions in multiple organs. ${ }^{100}$ A study of cultured endothelial cells (ECs) confirmed these observations. Inhibiting eNOS in ECs reduced NO and induced endothelial dysfunction. ECs expressed signals for growth of connective tissue, microvascular rarefaction and fibrosis. ${ }^{101}$ In light of the foregoing findings and background, inappropriate expression of NOS isoformsduring 5ARI use or after discontinuation - could underlie pathological neoangiogenesis following hypoxia.

A low DHT environment or off-target effects of 5ARIs could affect other angiogenic factors. Giatti et al. identified an off-target effect of finasteride on 
phenylethanolamine $N$-methyltransferase (PNMT), a limiting enzyme for the production of epinephrine (EPI) from norepinephrine. ${ }^{102}$ Catecholamines including EPI have been found to have a mediating role in angiogenesis. ${ }^{103-105} \mathrm{~A}$ study of bovine aortic endothelial cells (BAECs) found that hypoxia induced BAECs to produce PNMT. Separately, inhibition of a different catecholamine-producing enzyme impaired revascularization after ischemia, suggesting a role of catecholamines in angiogenesis. Sorriento et al. proposed that catecholamine release is an autoregulatory mechanism of ECs to initiate angiogenesis following hypoxia. ${ }^{106}$

In summary, demonstrated effects of 5ARIs on VEGF, NOS isoforms or PNMT could disrupt vascular homeostasis in several ways: by altering physiological angiogenesis, impairing vascular repair mechanisms, and inducing a compensatory rebound of angiogenic factors after 5ARI discontinuation.

\section{Systemic progression of PD-5ARI}

We have explored two complementary mechanisms for the pathogenesis of PD5ARI: androgen sensitivity of angiogenesis, and altered expression of angiogenic factors. A conundrum remains: how does PD-5ARI progress in a systemic manner? As illustrated in Figure 1B, damage in one organ or system might result in proinflammatory activity spreading to other organs and tissues. As an example, the "vicious progression" of CKD includes a proinflammatory component ${ }^{62}$ which may have impacts beyond the kidney. CKD has been associated with elevated risk of stroke ${ }^{107,108}$ and cerebrovascular disease. ${ }^{109,110}$ Marini et al. proposed that several factors, including chronic inflammation and endothelial dysfunction, additively increase the risk of renal dysfunction leading to cerebral small vessel disease. They described CKD patients as having a "systemic proinflammatory status."109

Rapid gum recession has been anecdotally associated with PD-5ARI, although the only known study of dental effects of finasteride, with 84 participants, did not identify this symptom. ${ }^{83}$ In a recent review on systemic aspects of periodontal disease, Celik \& Kantarci note that hypoxia may trigger a cascade of pathological angiogenesis and inflammatory processes, contributing to the progression of periodontal disease. ${ }^{111}$ Their conclusion notes: "The relationship between periodontal diseases and systemic 
inflammatory diseases includes uncontrolled inflammation. The interaction of distant tissues and organs via the vascular network and common inflammatory mediators, which may trigger the systemic inflammation in the circulation, make this link even more probable." 111

To summarize, recent research supports a link from kidney dysfunction to an elevated risk of cerebrovascular events, owing in part to proinflammatory activity and potentially systemic endothelial dysfunction. Likewise, periodontal disease is implicated in systemic inflammatory disease. The link is proposed to result from a cascade of hypoxia, endothelial dysfunction and inflammation.

Figure 1B represents a hypothesis for the systemic spread of a 5ARI-mediated pathological process. There are two nested vicious cycles: one at the local tissue level, involving vascular rarefaction, oxidative stress and inflammation; and the other at the systemic level, where proinflammatory mediators spread via the vascular network, inducing a systemic endothelial dysfunction. This may induce microvascular stress in other organs and tissues, setting off the same vicious cycle. Diviccaro et al. reported evidence of a proinflammatory effect of finasteride, both during treatment and after withdrawal. mRNA levels of tumor necrosis factor alpha (TNF-a) were significantly increased at the end of the finasteride treatment period compared to controls. ${ }^{77}$ Glial fibrillary acidic protein (GFAP) immunoreactive astrocytes, considered a biomarker for neuroinflammation and brain injury, ${ }^{112}$ were elevated in the dentate gyrus of hippocampus of rats 1 month after withdrawal from finasteride, compared to controls. ${ }^{77}$ In a study of the effects of finasteride on kidney tissue of rats, Baig et al. found "huge concentrations" of T cells and B cells around atrophic, pathologically changed tubules of the treatment group. IL-6 was also expressed in pathologically changed structures, as well as in renal corpuscles and epithelial cells of the nephron. ${ }^{66}$ These findings lend preliminary support to a hypothesis that injury, inflammation and immune activation in one organ could progress to a systemic endothelial dysfunction, putting other organs and tissues at risk of similar damage. Given the observation that PD-5ARI stabilizes after several months to one year, systemic endothelial dysfunction may eventually remit — though the injuries it induced may be irreversible. 


\section{Neuroendocrine, microbiotic and epigenetic changes associated with 5ARI exposure}

Human and animal studies have identified differences in neuroactive steroid levels, gut microbiota composition and gene expression persisting after discontinuation of finasteride. ${ }^{32,77,91,113,114}$ In an animal model, Giatti et al. identified neuroendocrine abnormalities 30 days after discontinuation of finasteride treatment: upregulation of androgen receptor in cerebral cortex; increased dihydroprogesterone in cerebellum; and downregulation of two GABA-A receptor subunits in cerebral cortex. ${ }^{113}$ The mechanism for the emergence of these alterations is not clear. A phenomenon called "hypoxic memory" refers to epigenetic changes subsequent to hypoxia and ischemia. ${ }^{115}$ Research has identified epigenetic changes as both cause and consequence of cerebral ischemia and stroke. ${ }^{116,117}$ Therefore it is conceivable that ischemia could lead to altered expression of neurosteroidogenic enzymes and neuroactive steroids.

A recent study found widespread epigenetic changes in penile tissue biopsies of post-5ARI patients with long-term symptoms. ${ }^{91}$ Here too, hypoxic memory and epigenetic consequences of ischemia could explain the emergence of such changes.

The ischemia-reperfusion hypothesis is not incompatible with changes in gut microbiota composition found in finasteride-treated animals. ${ }^{19}$ A review has identified "two-way communication" between the gut and brain in ischemic stroke. ${ }^{118}$

In summary, 5ARI-mediated changes in the neuroendocrine system, microbiome and epigenome could conceivably be downstream consequences of microvasculopathy or ischemia-reperfusion injury (Figure 9).

\section{Tentative implications for diagnosis and treatment}

Following are exploratory remarks related to an unproven hypothesis; they are not intended to be a substitute for medical advice, diagnosis or treatment.

Tentative implications for diagnosis

A focus on symptoms and a proposed syndrome persisting after discontinuation of 5ARIs has provoked consternation and skepticism. ${ }^{7}$ In the present formulation of PD5ARI, symptoms are manifestations of organ or system dysfunctions, which in turn arose from tissue injuries and their sequelae. Rather than taking a snapshot of symptoms at the 
time of a consultation, clinicians might explore the "movie" of how dysfunctions emerged over time (Figure 8). The patient could be prompted for histories of sexual function, neuropsychiatric well-being, cognition, sleep, and other areas. These developments should be integrated with the timeline of beginning and discontinuing 5ARIs (including interruptions and changes in product and dosage). Figures 6 and 7 and Table 4 provide examples of how these several dimensions may be represented and integrated.

There is an opportunity to seek diagnostic signs of putative injuries underlying dysfunctions of PD-5ARI. Tissue alterations such as increased collagen, fibrosis and neuropathy may primarily occur at the cellular level, presenting a challenge given the limitations of imaging techniques. Duplex ultrasonography and magnetic resonance imaging (MRI) have been used to assess penile vascular function and tissue composition. ${ }^{119-121}$ Diagnostic techniques for cognate diseases such as stroke and microvasculopathies might be explored (Table 4, column 3).

\section{$\underline{\text { Tentative implications for treatment }}$}

Treatments for the proposed model of PD-5ARI might explore those used for cognate diseases and conditions such as Peyronie's disease, penile fibrosis, penile injury, stroke, ${ }^{122}$ kidney disease ${ }^{60,62,63}$ and retinopathies (Table 4, column 3). In men with nonsurgical erectile dysfunction, hyperbaric oxygen therapy was found to induce angiogenesis and improve erectile function. ${ }^{123}$ Penile revascularization is one of several treatments available for vasculogenic ED. ${ }^{124}$ Therapies for Peyronie's disease and penile fibrosis might be adapted. ${ }^{125}$ Stem cell therapy for penile fibrosis has been explored. ${ }^{126}$ Penile tissue engineering has been explored in animal models. ${ }^{127}$

\section{Research directions}

Figure 1B suggests two potential lines of research: one investigating the inner loop describing local progression, and another investigating the outer loop describing the systemic spread of inflammation and endothelial dysfunction. Regarding the inner loop, is there a differential risk of 5ARI-mediated microvasculopathy based on age, genetics, epigenetics and drug exposure patterns? Techniques used by Lecce et al. ${ }^{89}$ might be adapted to observe the effects of 5ARI administration and discontinuation on dermal 
fibroblasts of younger and older men, including levels of HIF-1a, VEGF and eNOS, as well as inflammatory markers TNF-a, IL-6 and TGF- $\beta$. A hypoxia-on-a-chip model has been used to observe the effects of hypoxia on tissue in a controlled environment. ${ }^{128}$

A cohort study identified duration of finasteride use as the strongest predictor of young men developing persistent erectile dysfunction after discontinuation. ${ }^{129}$ Future research could explore whether prolonged or irregular use of 5ARIs might progressively degrade and disrupt vascular homeostasis, leading to the pathological inner loop in Figure $1 B$.

Investigation of the outer loop representing systemic progression seems more challenging. Researchers could draw on approaches used to study systemic inflammation and endothelial dysfunction. ${ }^{130,131}$

\section{Conclusion}

It has been proposed that PD-5ARI emerges from two nested vicious cycles. Locally within tissue or an organ, drug-mediated disturbance of vascular homeostasis may induce a vicious cycle of microvascular rarefaction, tissue injury, oxidative stress and inflammation. This progression may lead to alterations such as apoptosis, fibrosis, atrophy, structural changes, damage to neural signaling pathways and, consequently, organ dysfunction. Inflammatory mediators may also spread via the vascular network, leading to an episode of endothelial dysfunction. These systemic conditions may in turn trigger a similar vicious cycle in other organs and tissues such as the limbic system, eyes, inner ear, kidneys and gums. Finally, discontinuation of 5ARI use after tissue injury might cause a rebound in angiogenic factors such as VEGF, further disrupting neoangiogenesis.

The hypothesis accounts for some of the very properties of PD-5ARI that have led some to question its validity: dysfunctions in multiple systems; treatment-resistance; lack of abnormalities in lab tests; and high variability in symptoms, severity and course. In this reconceptualization, dysfunctions are merely a downstream consequence of prior injuries. This hypothesis may be reconciled with previous findings of epigenetic, neuroendocrine and microbiotic changes associated with prior use of 5ARIs. 


\section{Appendix: Methodological note on the use of adverse event data}

$\mathrm{AE}$ data has numerous limitations and caveats including underreporting, ${ }^{132,133}$ overreporting under certain conditions, differing sources, lack of follow-up and cooccurring conditions and drugs. In this paper, AE data has been filtered fairly strictly to minimize confounding factors, and is considered in the context of published research. It should not be taken as conclusive or comprehensive on its own, nor does it reveal prevalence. With these cautions and measures in place, AE data can reasonably be used as a means of exploring and developing a hypothesis.

To derive clusters of adverse events of finasteride among younger men, the top 30 AEs from 2018-2020 were analyzed (Table 1). This relatively short period reflects a recent understanding of potential impacts of 5ARIs, with lower variation in AE terms used. This period likely excludes litigation-related reports since the vast majority of plaintiffs in Propecia litigation accepted a settlement agreement in $2018 .{ }^{134}$ In targeted explorations of genitourinary and vascular AEs, a different data set was used, spanning the years 2000 2020. This longer period provides greater power in detecting less-common events. While a signal analysis has not been performed, AE counts are compared with those of minoxidil since it has a similar indication and is used by a similar population as finasteride. 


\section{Supplementary materials}

A Supplement and adverse event data files are available at osf.io/mn7rj

\section{Competing interests}

The author declares no competing interests. The author has contributed funds towards research on adverse effects of finasteride by Drs. Roberto Melcangi, Silvia Giatti and colleagues at the University of Milan. Their work has been cited in this manuscript. They had no role in the preparation of this manuscript.

\section{Permissions}

The main flow of Figure 1B has been adapted from Figure 1 in Textor \& Lerman ${ }^{62}$ with permission of the corresponding author. Images in Figure 2 from Zhang et al. ${ }^{22}$ are used under license from Elsevier. Images in Figure 3 from Da Silva et al. ${ }^{20}$ are used under CC BY-NC-SA 4.0 license. Images in Figure 4 from Shen et al. ${ }^{25}$ are used with permission of Asian Journal of Andrology. The illustration in Figure 5 is used under license from Adobe Stock.

\section{Contact information}

Correspondence may be addressed to etiopathology@fastmail.com.

\section{Disclaimer}

This manuscript describes an unproven hypothesis which does not reflect medical consensus. Its purpose is to stimulate discussion and further research on lasting dysfunctions after use of 5ARIs. The information provided is not intended to be a substitute for medical advice, diagnosis or treatment. 


\section{References}

1. Nguyen DD, Marchese M, Cone EB, et al. Investigation of Suicidality and Psychological Adverse Events in Patients Treated With Finasteride. JAMA Dermatol. 2021;157(1):35-42. doi:10.1001/jamadermatol.2020.3385

2. Baas WR, Butcher MJ, Lwin A, et al. A Review of the FAERS Data on 5-Alpha Reductase Inhibitors: Implications for Postfinasteride Syndrome. Urology. 2018;120:143-149. doi:10.1016/j.urology.2018.06.022

3. Harrell MB, Ho K, Te AE, Kaplan SA, Chughtai B. An evaluation of the federal adverse events reporting system data on adverse effects of 5-alpha reductase inhibitors [published correction appears in World $\mathrm{J}$ Urol. 2021 Nov;39(11):4293]. World J Urol. 2021;39(4):1233-1239. doi:10.1007/s00345-020-03314-9

4. Trüeb RM, Régnier A, Dutra Rezende H, Gavazzoni Dias MFR. Post-Finasteride Syndrome: An Induced Delusional Disorder with the Potential of a Mass Psychogenic Illness? Skin Appendage Disord. 2019;5(5):320-326. doi:10.1159/000497362

5. Ho RS. Ongoing Concerns Regarding Finasteride for the Treatment of Male-Pattern Androgenetic Alopecia. JAMA Dermatol. 2021;157(1):25-26. doi:10.1001/jamadermatol.2020.3384

6. Basaria S, Jasuja R, Huang G, et al. Characteristics of Men Who Report Persistent Sexual Symptoms After Finasteride Use for Hair Loss. J Clin Endocrinol Metab. 2016;101(12):4669-4680. doi:10.1210/jc.2016-2726

7. Gray SL, Semla TP. Post-finasteride syndrome. BMJ. 2019;366:15047. doi:10.1136/bmj.15047

8. Fertig R, Shapiro J, Bergfeld W, Tosti A. Investigation of the Plausibility of 5-Alpha-Reductase Inhibitor Syndrome. Skin Appendage Disord. 2017;2(3-4):120-129. doi:10.1159/000450617

9. Butcher M, Baas W, Lwin A, et al. MP89-08 Post-finasteride syndrome: Real or imagined? Journal of Urology. 2016;195(4S):e1139. doi:10.1016/j.juro.2016.02.2469

10. Chervenak FA, McCullough LB, Hale RW. Guild interests: an insidious threat to professionalism in obstetrics and gynecology. Am J Obstet Gynecol. 2018;219(6):581-584. doi:10.1016/j.ajog.2018.09.007

11. Traish AM, Hassani J, Guay AT, Zitzmann M, Hansen ML. Adverse side effects of $5 \alpha$-reductase inhibitors therapy: persistent diminished libido and erectile dysfunction and depression in a subset of patients. $J$ Sex Med. 2011;8(3):872-884. doi:10.1111/j.1743-6109.2010.02157.x

12. Irwig MS, Kolukula S. Persistent sexual side effects of finasteride for male pattern hair loss. $J$ Sex Med. 2011;8(6):1747-1753. doi:10.1111/j.1743-6109.2011.02255.x

13. Schifano N, Capogrosso P, Boeri L, et al. Is finasteride intake associated with penile curvature/Peyronie's disease? Assessment of both the Food and Drug Administration (FDA) and the European Medicines Agency (EMA) pharmacovigilance databases. Eur Urol Open Sci. 2021;32:S18. doi:10.1016/S26661683(21)00727-8

14. American Psychiatric Association. Diagnostic and Statistical Manual of Mental Disorders, Fifth Edition. American Psychiatric Association Publishing; 2013.

15. Cash H, Rae CD, Steel AH, Winkler A. Internet Addiction: A Brief Summary of Research and Practice. Curr Psychiatry Rev. 2012;8(4):292-298. doi:10.2174/157340012803520513

16. Lekas AG, Lazaris AC, Chrisofos M, et al. Finasteride effects on hypoxia and angiogenetic markers in benign prostatic hyperplasia. Urology. 2006;68(2):436-441. doi:10.1016/j.urology.2006.03.038

17. Mehmet H, Edwards AD. Hypoxia, ischaemia, and apoptosis. Arch Dis Child Fetal Neonatal Ed. 1996;75(2):F73-75. doi:10.1136/fn.75.2.f73 
18. Cowled P, Fitridge R. Pathophysiology of Reperfusion Injury. In: Fitridge R, Thompson M, eds. Mechanisms of Vascular Disease: A Reference Book for Vascular Specialists. University of Adelaide Press; 2011. Accessed January 22, 2022. http://www.ncbi.nlm.nih.gov/books/NBK534267/

19. Kalogeris T, Baines CP, Krenz M, Korthuis RJ. Ischemia/Reperfusion. Compr Physiol. 2016;7(1):113170. doi:10.1002/cphy.c160006

20. Da Silva MHA, Costa WS, B Sampaio FJ, De Souza DB. The corpus cavernosum after treatment with dutasteride or finasteride: A histomorphometric study in a benign prostatic hyperplasia rodent model. Asian J Androl. 2018;20(5):505-510. doi:10.4103/aja.aja_28_18

21. Zhang $\mathrm{M}, \mathrm{Wu} \mathrm{W}$, Zhang $\mathrm{C}$, et al. Effects of Oral Finasteride on Erectile Function in a Rat Model. The Journal of Sexual Medicine. 2012;9(5):1328-1336. doi:10.1111/j.1743-6109.2012.02661.x

22. Zhang MG, Wang XJ, Shen ZJ, Gao PJ. Long-term oral administration of $5 \alpha$-reductase inhibitor attenuates erectile function by inhibiting autophagy and promoting apoptosis of smooth muscle cells in corpus cavernosum of aged rats. Urology. 2013;82(3):743.e9-15. doi:10.1016/j.urology.2013.02.045

23. Kilic S, Kolukcu E, Erdemir F, Benli I, Arici A. The Effects of Oral 5-alpha Reductase Inhibitors on Penile Intracavernosal Pressures and Penile Morphology in Rat Model. Urol J. 2019;16(2):205-211. doi:10.22037/uj.v0i0.4164

24. Sung HH, Yu J, Kang SJ, et al. Persistent Erectile Dysfunction after Discontinuation of 5-Alpha Reductase Inhibitor Therapy in Rats Depending on the Duration of Treatment. World J Mens Health. 2019;37(2):240-248. doi:10.5534/wjmh.180082

25. Shen ZJ, Zhou XL, Lu YL, Chen ZD. Effect of androgen deprivation on penile ultrastructure. Asian $J$ Androl. 2003;5(1):33-36. http://www.asiaandro.com/archive/1008-682X/5/33.htm

26. Enatsu N, Chiba K, Sumii K, et al. Dutasteride-mediated morphological changes in the genitourinary tract associated with altered expression patterns of the androgen and estrogen receptors in male rats. Andrology. 2017;5(2):347-353. doi:10.1111/andr.12297

27. Gul A, Altinay S, Kabasakal L, Yavuz A, Semercioz A, Serefoglu EC. Effect of tadalafil on penile nitric oxide synthase and corporal smooth muscle in rats under dutasteride treatment. Aging Male. 2020;23(2):161-167. doi:10.1080/13685538.2020.1739019

28. Shen ZJ, Chen SW, Lu YL, et al. Preliminary study on androgen dependence of calcitonin gene-related peptide in rat penis. Asian J Androl. 2005;7(1):55-59. doi:10.1111/j.1745-7262.2005.00003.x

29. Liu L, Zhao S, Li F, et al. Effect of $5 \alpha$-Reductase Inhibitors on Sexual Function: A Meta-Analysis and Systematic Review of Randomized Controlled Trials. J Sex Med. 2016;13(9):1297-1310. doi:10.1016/j.jsxm.2016.07.006

30. Oztekin CV, Gur S, Abdulkadir NA, et al. Incomplete recovery of erectile function in rat after discontinuation of dual 5-alpha reductase inhibitor therapy. J Sex Med. 2012;9(7):1773-1781. doi:10.1111/j.1743-6109.2012.02759.x

31. Khera M, Than JK, Anaissie J, et al. Penile vascular abnormalities in young men with persistent side effects after finasteride use for the treatment of androgenic alopecia. Transl Androl Urol. 2020;9(3):12011209. doi:10.21037/tau.2020.03.21

32. Melcangi RC, Santi D, Spezzano R, et al. Neuroactive steroid levels and psychiatric and andrological features in post-finasteride patients. J Steroid Biochem Mol Biol. 2017;171:229-235. doi:10.1016/j.jsbmb.2017.04.003

33. Garreton AS, Valzacchi GR, Layus O. Post-Finasteride Syndrome: About 2 Cases and Review of the Literature. Andrology (Los Angel). 2016;05(2). doi:10.4172/2472-1212.1000170

34. Ferrara N. Vascular endothelial growth factor: basic science and clinical progress. Endocr Rev. 2004;25(4):581-611. doi:10.1210/er.2003-0027 
35. Majmundar AJ, Wong WJ, Simon MC. Hypoxia-inducible factors and the response to hypoxic stress. Mol Cell. 2010;40(2):294-309. doi:10.1016/j.molcel.2010.09.022

36. Melincovici CS, Boşca AB, Şuşman S, et al. Vascular endothelial growth factor (VEGF) - key factor in normal and pathological angiogenesis. Rom J Morphol Embryol. 2018;59(2):455-467.

37. Ziello JE, Jovin IS, Huang Y. Hypoxia-Inducible Factor (HIF)-1 regulatory pathway and its potential for therapeutic intervention in malignancy and ischemia. Yale J Biol Med. 2007;80(2):51-60.

38. Lähteenvuo J, Rosenzweig A. Effects of aging on angiogenesis. Circ Res. 2012;110(9):1252-1264. doi:10.1161/CIRCRESAHA.111.246116

39. Nour M, Scalzo F, Liebeskind DS. Ischemia-reperfusion injury in stroke. Interv Neurol. 2013;1(3-4):185199. doi:10.1159/000353125

40. Mayer G. Capillary rarefaction, hypoxia, VEGF and angiogenesis in chronic renal disease. Nephrol Dial Transplant. 2011;26(4):1132-1137. doi:10.1093/ndt/gfq832

41. Venkatachalam MA, Weinberg JM, Kriz W, Bidani AK. Failed Tubule Recovery, AKI-CKD Transition, and Kidney Disease Progression. J Am Soc Nephrol. 2015;26(8):1765-1776. doi:10.1681/ASN.2015010006

42. Deering RE, Bigler SA, Brown M, Brawer MK. Microvascularity in benign prostatic hyperplasia. Prostate. 1995;26(3):111-115. doi:10.1002/pros.2990260302

43. Stefanou D, Batistatou A, Kamina S, Arkoumani E, Papachristou DJ, Agnantis NJ. Expression of vascular endothelial growth factor (VEGF) and association with microvessel density in benign prostatic hyperplasia and prostate cancer. In Vivo. 2004;18(2):155-160.

44. Jackson MW, Bentel JM, Tilley WD. Vascular endothelial growth factor (VEGF) expression in prostate cancer and benign prostatic hyperplasia. J Urol. 1997;157(6):2323-2328.

45. Pareek G, Shevchuk M, Armenakas NA, et al. The effect of finasteride on the expression of vascular endothelial growth factor and microvessel density: a possible mechanism for decreased prostatic bleeding in treated patients. $J$ Urol. 2003;169(1):20-23. doi:10.1097/01.ju.0000039923.75777.91

46. Donohue JF, Hayne D, Karnik U, Thomas DR, Foster MC. Randomized, placebo-controlled trial showing that finasteride reduces prostatic vascularity rapidly within 2 weeks. BJU Int. 2005;96(9):1319-1322. doi:10.1111/j.1464-410X.2005.05849.x

47. Tian $\mathrm{H}$, Zhao $\mathrm{C}, \mathrm{Wu} \mathrm{H}$, et al. Finasteride reduces microvessel density and expression of vascular endothelial growth factor in renal tissue of diabetic rats. Am J Med Sci. 2015;349(6):516-520. doi:10.1097/MAJ.0000000000000451

48. George JN, Nester CM. Syndromes of thrombotic microangiopathy. N Engl J Med. 2014;371(7):654-666. doi:10.1056/NEJMra1312353

49. Levi M, Sivapalaratnam S. An overview of thrombotic complications of old and new anticancer drugs. Thromb Res. 2020;191 Suppl 1:S17-S21. doi:10.1016/S0049-3848(20)30391-1

50. Bollée G, Patey N, Cazajous G, et al. Thrombotic microangiopathy secondary to VEGF pathway inhibition by sunitinib. Nephrol Dial Transplant. 2009;24(2):682-685. doi:10.1093/ndt/gfn657

51. Eremina V, Jefferson JA, Kowalewska J, et al. VEGF inhibition and renal thrombotic microangiopathy. $N$ Engl J Med. 2008;358(11):1129-1136. doi:10.1056/NEJMoa0707330

52. Touyz RM, Herrmann SMS, Herrmann J. Vascular toxicities with VEGF inhibitor therapies-focus on hypertension and arterial thrombotic events. J Am Soc Hypertens. 2018;12(6):409-425. doi:10.1016/j.jash.2018.03.008 
53. Kuenen BC, Levi M, Meijers JCM, et al. Analysis of coagulation cascade and endothelial cell activation during inhibition of vascular endothelial growth factor/vascular endothelial growth factor receptor pathway in cancer patients. Arterioscler Thromb Vasc Biol. 2002;22(9):1500-1505. doi:10.1161/01.atv.0000030186.66672.36

54. Ayodele O, Cabral HJ, McManus D, Jick S. The Risk of Venous Thromboembolism (VTE) in Men with Benign Prostatic Hyperplasia Treated with 5-Alpha Reductase Inhibitors (5ARIs). Clin Epidemiol. 2021;13:661-673. doi:10.2147/CLEP.S317019

55. Loke YK, Ho R, Smith M, et al. Systematic review evaluating cardiovascular events of the 5-alpha reductase inhibitor - Dutasteride. J Clin Pharm Ther. 2013;38(5):405-415. doi:10.1111/jcpt.12080

56. Shores MM, Arnold AM, Biggs ML, et al. Testosterone and dihydrotestosterone and incident ischaemic stroke in men in the Cardiovascular Health Study. Clin Endocrinol (Oxf). 2014;81(5):746-753. doi: $10.1111 /$ cen. 12452

57. Tsuji Y, Nakayama T, Bono K, Kitamura M, Imafuku I. [Two cases of stroke associated with the use of finasteride, an approved drug for male-pattern hair loss in Japan]. Rinsho Shinkeigaku. 2014;54(5):423428. doi:10.5692/clinicalneurol.54.423

58. Choi BK, Cheon K, Cho BH, Jung JW, Lee KY. Cerebral Venous Sinus Thrombosis Associated with Dutasteride Use. Yonsei Med J. 2020;61(6):553-555. doi:10.3349/ymj.2020.61.6.553

59. Kang DW, Jeong HG, Kim HR, et al. Finasteride Induced Cerebral Venous Thrombosis. Journal of the Korean Neurological Association. 2015;33(3):238-240.

60. Patschan D, Kribben A, Müller GA. Postischemic microvasculopathy and endothelial progenitor cellbased therapy in ischemic AKI: update and perspectives. Am J Physiol Renal Physiol. 2016;311(2):F382394. doi:10.1152/ajprenal.00232.2016

61. Liu Y. Cellular and molecular mechanisms of renal fibrosis. Nat Rev Nephrol. 2011;7(12):684-696. doi:10.1038/nrneph.2011.149

62. Textor SC, Lerman LO. The Role of Hypoxia in Ischemic Chronic Kidney Disease. Semin Nephrol. 2019;39(6):589-598. doi:10.1016/j.semnephrol.2019.10.008

63. Tanaka S, Tanaka T, Nangaku M. Hypoxia and Dysregulated Angiogenesis in Kidney Disease. Kidney Dis (Basel). 2015;1(1):80-89. doi:10.1159/000381515

64. Holderied A, Kraft F, Marschner JA, Weidenbusch M, Anders HJ. "Point of no return" in unilateral renal ischemia reperfusion injury in mice. J Biomed Sci. 2020;27(1):34. doi:10.1186/s12929-020-0623-9

65. Da Silva MHA, Estrada JHD, Gregório BM, Sampaio FJB, De Souza DB. Does treatment with dutasteride or finasteride has [sic] impact on renal morphology? Experimental study. Acta Cir Bras. 2021;36(7):e360703. doi:10.1590/ACB360703

66. Baig MS, Kolasa-Wołosiuk A, Pilutin A, et al. Finasteride-Induced Inhibition of $5 \alpha$-Reductase Type 2 Could Lead to Kidney Damage-Animal, Experimental Study. Int J Environ Res Public Health. 2019;16(10):E1726. doi:10.3390/ijerph16101726

67. Goligorsky MS. Microvascular rarefaction. Organogenesis. 2010;6(1):1-10.

68. Wadowski PP, Schörgenhofer C, Rieder T, et al. Microvascular rarefaction in patients with cerebrovascular events. Microvasc Res. 2022;140:104300. doi:10.1016/j.mvr.2021.104300

69. Chiriacò G, Cauci S, Mazzon G, Trombetta C. An observational retrospective evaluation of 79 young men with long-term adverse effects after use of finasteride against androgenetic alopecia. Andrology. 2016;4(2):245-250. doi:10.1111/andr.12147

70. Norata GD, Tibolla G, Seccomandi PM, Poletti A, Catapano AL. Dihydrotestosterone decreases tumor necrosis factor-alpha and lipopolysaccharide-induced inflammatory response in human endothelial cells. $J$ Clin Endocrinol Metab. 2006;91(2):546-554. doi:10.1210/jc.2005-1664 
71. Cipriani P, Marrelli A, Liakouli V, Di Benedetto P, Giacomelli R. Cellular players in angiogenesis during the course of systemic sclerosis. Autoimmun Rev. 2011;10(10):641-646. doi:10.1016/j.autrev.2011.04.016

72. Cantatore FP, Maruotti N, Corrado A, Ribatti D. Angiogenesis Dysregulation in the Pathogenesis of Systemic Sclerosis. Biomed Res Int. 2017;2017:5345673. doi:10.1155/2017/5345673

73. Adigun R, Goyal A, Bansal P, Hariz A. Systemic Sclerosis. In: StatPearls. StatPearls Publishing; 2022. Accessed January 20, 2022. http://www.ncbi.nlm.nih.gov/books/NBK430875/

74. Ota Y, Kuwana M. Endothelial cells and endothelial progenitor cells in the pathogenesis of systemic sclerosis. Eur J Rheumatol. 2020;7(Suppl 3):S139-S146. doi:10.5152/eurjrheum.2019.19158

75. Jaeger VK, Walker UA. Erectile Dysfunction in Systemic Sclerosis. Curr Rheumatol Rep. 2016;18(8):49. doi:10.1007/s11926-016-0597-5

76. Paredes RG. Medial preoptic area/anterior hypothalamus and sexual motivation. Scand J Psychol. 2003;44(3):203-212. doi:10.1111/1467-9450.00337

77. Diviccaro S, Giatti S, Borgo F, et al. Treatment of male rats with finasteride, an inhibitor of 5alphareductase enzyme, induces long-lasting effects on depressive-like behavior, hippocampal neurogenesis, neuroinflammation and gut microbiota composition. Psychoneuroendocrinology. 2019;99:206-215. doi:10.1016/j.psyneuen.2018.09.021

78. Fraunfelder FT, Fraunfelder FW. Chapter 11 - Hormones and Drugs Affecting Hormonal Mechanisms. In: Fraunfelder FT, Fraunfelder FW, eds. Drug-Induced Ocular Side Effects (Eighth Edition). Elsevier; 2021:241-264. doi:10.1016/B978-0-323-65375-6.00011-6

79. Chatziralli IP, Peponis V, Parikakis E, et al. Risk factors for intraoperative floppy iris syndrome: a prospective study. Eye (Lond). 2016;30(8):1039-1044. doi:10.1038/eye.2016.122

80. Nguyen BJ, Meer E, Gupta AS, et al. The effect of finasteride on dry eye disease. In: ARVO 2022 Abstracts. Association for Research in Vision and Ophthalmology; 2022. Accessed May 10, 2022. https://arvo2022.arvo.org/abstracts

81. Nguyen LH, Makino A, Namkoong P, Yiannakou Y, Narain K. Finasteride Induced Clinical Ocular Toxicity. Invest Ophthalmol Vis Sci. 2018;59(9):2655. Accessed January 20, 2022. https://iovs.arvojournals.org/article.aspx?articleid=2690754

82. Narain K. A Letter regarding Finasteride. South Bay Retina. Published Undated. Accessed January 25, 2022. https://www.southbayretina.com/a-letter-regarding-finasteride/

83. Paunica S, Giurgiu M, Vasilache A, et al. Finasteride adverse effects and post-finasteride syndrome; implications for dentists. Journal of Mind and Medical Sciences. 2016;3(1):71-79. https://scholar.valpo.edu/jmms/vol3/iss1/9/

84. Paciaroni M, Bogousslavsky J. Chapter 1 The history of stroke and cerebrovascular disease. In: Handbook of Clinical Neurology. Vol 92. Elsevier; 2008:3-28. doi:10.1016/S0072-9752(08)01901-5

85. Stroke Recovery Prognosis: What Will the Outcome Be? Flint Rehab. Published July 16, 2019. Accessed January 22, 2022. https://www.flintrehab.com/stroke-recovery-prognosis/

86. Yoshida S, Ikeda Y, Aihara K. Roles of the Androgen--Androgen Receptor System in Vascular Angiogenesis. J Atheroscler Thromb. 2016;23(3):257-265. doi:10.5551/jat.31047

87. Sieveking DP, Lim P, Chow RWY, et al. A sex-specific role for androgens in angiogenesis. $J$ Exp Med. 2010;207(2):345-352. doi:10.1084/jem.20091924

88. Mirone V, Imbimbo C, Fusco F, Verze P, Creta M, Tajana G. Androgens and morphologic remodeling at penile and cardiovascular levels: a common piece in complicated puzzles? Eur Urol. 2009;56(2):309-316. doi:10.1016/j.eururo.2008.12.037 
89. Lecce L, Lam YT, Lindsay LA, et al. Aging impairs VEGF-mediated, androgen-dependent regulation of angiogenesis. Mol Endocrinol. 2014;28(9):1487-1501. doi:10.1210/me.2013-1405

90. Ye Y, Li X, Zhang Y, Shen Z, Yang J. Androgen Modulates Functions of Endothelial Progenitor Cells through Activated Egr1 Signaling. Stem Cells Int. 2016;2016:7057894. doi:10.1155/2016/7057894

91. Howell S, Song W, Pastuszak A, Khera M. Differential Gene Expression in Post-Finasteride Syndrome Patients. J Sex Med. 2021;18(9):1479-1490. doi:10.1016/j.jsxm.2021.05.009

92. Lam YT, Lecce L, Tan JTM, Bursill CA, Handelsman DJ, Ng MKC. Androgen Receptor-Mediated Genomic Androgen Action Augments Ischemia-Induced Neovascularization. Endocrinology. 2016;157(12):4853-4864. doi:10.1210/en.2016-1301

93. Lam YT, Hsu CJ, Simpson PJL, et al. Androgens Stimulate EPC-Mediated Neovascularization and Are Associated with Increased Coronary Collateralization. Endocrinology. 2020;161(5):bqaa043. doi:10.1210/endocr/bqaa043

94. Shafighi M, Olariu R, Brun C, et al. The role of androgens on hypoxia-inducible factor (HIF)-1 $\alpha$-induced angiogenesis and on the survival of ischemically challenged skin flaps in a rat model. Microsurgery. 2012;32(6):475-481. doi:10.1002/micr.21996

95. Uchida M, Palmateer JM, Herson PS, DeVries AC, Cheng J, Hurn PD. Dose-dependent effects of androgens on outcome after focal cerebral ischemia in adult male mice. J Cereb Blood Flow Metab. 2009;29(8):1454-1462. doi:10.1038/jcbfm.2009.60

96. Ungvari Z, Tarantini S, Kiss T, et al. Endothelial dysfunction and angiogenesis impairment in the ageing vasculature. Nat Rev Cardiol. 2018;15(9):555-565. doi:10.1038/s41569-018-0030-Z

97. Bosch-Marce M, Okuyama $\mathrm{H}$, Wesley JB, et al. Effects of aging and hypoxia-inducible factor-1 activity on angiogenic cell mobilization and recovery of perfusion after limb ischemia. Circ Res. 2007;101(12):1310-1318. doi:10.1161/CIRCRESAHA.107.153346

98. Bates DO. Vascular endothelial growth factors and vascular permeability. Cardiovasc Res. 2010;87(2):262-271. doi:10.1093/cvr/cvq105

99. Cooke JP. Endotheliopathy of Obesity. Circulation. 2020;142(4):380-383. doi:10.1161/CIRCULATIONAHA.120.047574

100. Cyr AR, Huckaby LV, Shiva SS, Zuckerbraun BS. Nitric Oxide and Endothelial Dysfunction. Critical Care Clinics. 2020;36(2):307-321. doi:10.1016/j.ccc.2019.12.009

101. O'Riordan E, Mendelev N, Patschan S, et al. Chronic NOS inhibition actuates endothelial-mesenchymal transformation. Am J Physiol Heart Circ Physiol. 2007;292(1):H285-294. doi:10.1152/ajpheart.00560.2006

102. Giatti S, Di Domizio A, Diviccaro S, et al. Three-Dimensional Proteome-Wide Scale Screening for the 5Alpha Reductase Inhibitor Finasteride: Identification of a Novel Off-Target. J Med Chem. 2021;64(8):4553-4566. doi:10.1021/acs.jmedchem.0c02039

103. Liu H, Sangkum L, Liu G, Green M, Li M, Kaye A. Effects of epinephrine on angiogenesis-related gene expressions in cultured rat cardiomyocytes. J Biomed Res. 2016;30(5):380-385. doi: $10.7555 / J B R .30 .20160024$

104. Chakroborty D, Goswami S, Basu S, Sarkar C. Catecholamines in the regulation of angiogenesis in cutaneous wound healing. FASEB J. 2020;34(11):14093-14102. doi:10.1096/fj.202001701R

105. Garg J, Feng YX, Jansen SR, et al. Catecholamines facilitate VEGF-dependent angiogenesis via $\beta 2$ adrenoceptor-induced Epac1 and PKA activation. Oncotarget. 2017;8(27):44732-44748. doi:10.18632/oncotarget.17267 
106. Sorriento D, Santulli G, Del Giudice C, Anastasio A, Trimarco B, Iaccarino G. Endothelial Cells Are Able to Synthesize and Release Catecholamines Both In Vitro and In Vivo. Hypertension.

2012;60(1):129-136. doi:10.1161/HYPERTENSIONAHA.111.189605

107. Ghoshal S, Freedman BI. Mechanisms of Stroke in Patients with Chronic Kidney Disease. Am J Nephrol. 2019;50(4):229-239. doi:10.1159/000502446

108. Chelluboina B, Vemuganti R. Chronic kidney disease in the pathogenesis of acute ischemic stroke. $J$ Cereb Blood Flow Metab. 2019;39(10):1893-1905. doi:10.1177/0271678X19866733

109. Marini S, Georgakis MK, Anderson CD. Interactions Between Kidney Function and Cerebrovascular Disease: Vessel Pathology That Fires Together Wires Together. Front Neurol. 2021;12:785273. doi:10.3389/fneur.2021.785273

110. Hanna RM, Ferrey A, Rhee CM, Kalantar-Zadeh K. Renal-Cerebral Pathophysiology: The Interplay Between Chronic Kidney Disease and Cerebrovascular Disease. J Stroke Cerebrovasc Dis. 2021;30(9):105461. doi:10.1016/j.jstrokecerebrovasdis.2020.105461

111. Celik D, Kantarci A. Vascular Changes and Hypoxia in Periodontal Disease as a Link to Systemic Complications. Pathogens. 2021;10(10):1280. doi:10.3390/pathogens 10101280

112. Li D, Liu X, Liu T, et al. Neurochemical regulation of the expression and function of glial fibrillary acidic protein in astrocytes. Glia. 2020;68(5):878-897. doi:10.1002/glia.23734

113. Giatti S, Foglio B, Romano S, et al. Effects of Subchronic Finasteride Treatment and Withdrawal on Neuroactive Steroid Levels and Their Receptors in the Male Rat Brain. Neuroendocrinology. 2016;103(6):746-757. doi:10.1159/000442982

114. Borgo F, Macandog AD, Diviccaro S, et al. Alterations of gut microbiota composition in post-finasteride patients: a pilot study. $J$ Endocrinol Invest. 2021;44(6):1263-1273. doi:10.1007/s40618-020-01424-0

115. Tanaka T. Epigenetic changes mediating transition to chronic kidney disease: Hypoxic memory. Acta Physiol (Oxf). 2018;222(4):e13023. doi:10.1111/apha.13023

116. Hu Z, Zhong B, Tan J, Chen C, Lei Q, Zeng L. The Emerging Role of Epigenetics in Cerebral Ischemia. Mol Neurobiol. 2017;54(3):1887-1905. doi:10.1007/s12035-016-9788-3

117. Liu X, Fan B, Chopp M, Zhang Z. Epigenetic Mechanisms Underlying Adult Post Stroke Neurogenesis. Int J Mol Sci. 2020;21(17):E6179. doi:10.3390/ijms21176179

118. Pluta R, Januszewski S, Czuczwar SJ. The Role of Gut Microbiota in an Ischemic Stroke. Int J Mol Sci. 2021;22(2):E915. doi:10.3390/ijms22020915

119. Aversa A, Crafa A, Greco EA, Chiefari E, Brunetti A, La Vignera S. The penile duplex ultrasound: How and when to perform it? Andrology. 2021;9(5):1457-1466. doi:10.1111/andr.13029

120. Kim J, Drury R, Morenas R, Raheem O. Pathophysiology and Grayscale Ultrasonography of Penile Corporal Fibrosis. Sex Med Rev. 2022;10(1):99-107. doi:10.1016/j.sxmr.2021.07.005

121. Lindquist CM, Nikolaidis P, Mittal PK, Miller FH. MRI of the penis. Abdom Radiol (NY). 2020;45(7):2001-2017. doi:10.1007/s00261-019-02301-y

122. Kuriakose D, Xiao Z. Pathophysiology and Treatment of Stroke: Present Status and Future Perspectives. Int J Mol Sci. 2020;21(20):E7609. doi:10.3390/ijms21207609

123. Hadanny A, Lang E, Copel L, et al. Hyperbaric oxygen can induce angiogenesis and recover erectile function. Int J Impot Res. 2018;30(6):292-299. doi:10.1038/s41443-018-0023-9

124. Shauly O, Gould DJ, Patel KM. Emerging nonsurgical and surgical techniques to treat erectile dysfunction: A systematic review of treatment options and published outcomes. J Plast Reconstr Aesthet Surg. 2019;72(4):532-538. doi:10.1016/j.bjps.2018.12.028 
125. Zhang F, Qin F, Yuan J. Molecular Mechanisms and Current Pharmacotherapy of Peyronie's Disease: A Review. Front Pharmacol. 2021;12:643641. doi:10.3389/fphar.2021.643641

126. Milenkovic U, Albersen M, Castiglione F. The mechanisms and potential of stem cell therapy for penile fibrosis. Nat Rev Urol. 2019;16(2):79-97. doi:10.1038/s41585-018-0109-7

127. Andrew TW, Kanapathy M, Murugesan L, Muneer A, Kalaskar D, Atala A. Towards clinical application of tissue engineering for erectile penile regeneration. Nat Rev Urol. 2019;16(12):734-744. doi:10.1038/s41585-019-0246-7

128. Kang YBA, Eo J, Bulutoglu B, Yarmush ML, Usta OB. Progressive hypoxia-on-a-chip: An in vitro oxygen gradient model for capturing the effects of hypoxia on primary hepatocytes in health and disease. Biotechnol Bioeng. 2020;117(3):763-775. doi:10.1002/bit.27225

129. Kiguradze T, Temps WH, Yarnold PR, et al. Persistent erectile dysfunction in men exposed to the $5 \alpha-$ reductase inhibitors, finasteride, or dutasteride. PeerJ. 2017;5:e3020. doi:10.7717/peerj.3020

130. Low A, Mak E, Rowe JB, Markus HS, O’Brien JT. Inflammation and cerebral small vessel disease: A systematic review. Ageing Res Rev. 2019;53:100916. doi:10.1016/j.arr.2019.100916

131. Daiber A, Steven S, Weber A, et al. Targeting vascular (endothelial) dysfunction. Br J Pharmacol. 2017;174(12):1591-1619. doi:10.1111/bph.13517

132. Lopez-Gonzalez E, Herdeiro MT, Figueiras A. Determinants of under-reporting of adverse drug reactions: a systematic review. Drug Saf. 2009;32(1):19-31. doi:10.2165/00002018-200932010-00002

133. Hazell L, Shakir SAW. Under-Reporting of Adverse Drug Reactions. Drug Saf. 2006;29(5):385-396. doi:10.2165/00002018-200629050-00003

134. Levine D. Judge orders Merck documents on anti-baldness drug Propecia unsealed. Reuters. https://www.reuters.com/business/healthcare-pharmaceuticals/judge-orders-merck-documents-antibaldness-drug-propecia-unsealed-2021-01-25/. Published January 25, 2021. Accessed February 4, 2022. 


$\begin{array}{ll}\text { Abbreviations in figure and table captions } \\ \text { 5ARI } & \text { 5-alpha reductase inhibitor } \\ \text { AE } & \begin{array}{l}\text { adverse event } \\ \text { DHT }\end{array} \\ \text { dihydrotestosterone } \\ \text { FAERS } & \begin{array}{l}\text { Federal Adverse Event Reporting System of the U.S. Food } \\ \text { and Drug Administration }\end{array} \\ \text { HIF-1a } & \text { hypoxia-inducible factor 1a } \\ \text { IL-6 } & \text { interleukin 6 } \\ \text { PD-5ARI } & \text { lasting dysfunctions after use of 5-a reductase inhibitors } \\ \text { PDE5 } & \text { phosphodiesterase type 5 } \\ \text { TBI } & \text { traumatic brain injury } \\ \text { TGF- } \beta & \text { transforming growth factor- } \beta \\ \text { TIA } & \text { transient ischemic attack } \\ \text { TNF-a } & \text { tumor necrosis factor-a } \\ \text { VEGF } & \text { vascular endothelial growth factor } \\ \text { VAE } & \text { vascular adverse event }\end{array}$


A

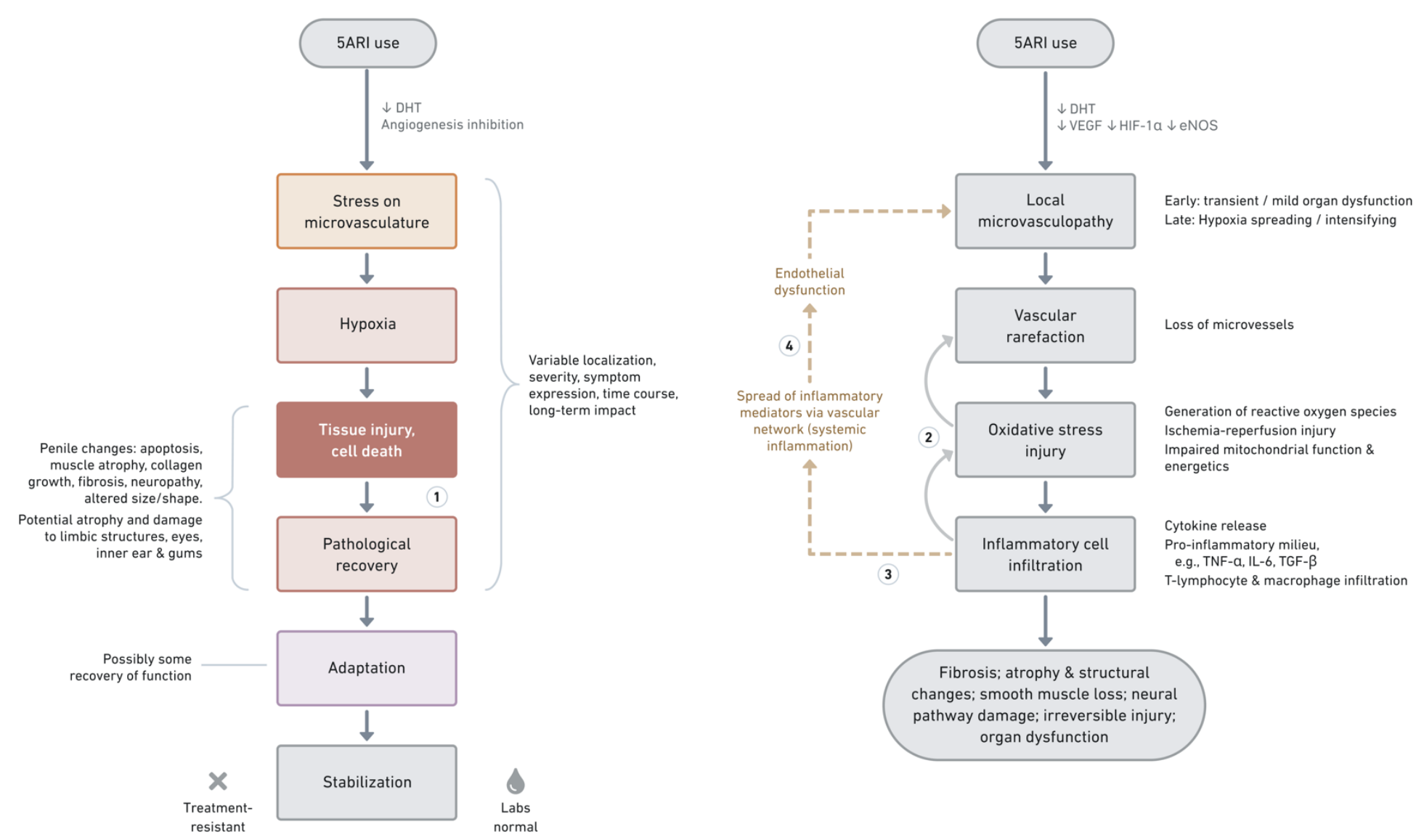

Fig. 1. Overview of proposed etiopathology of PD-5ARI. (A) Major stages of disease progression. (1) Tissue injury may induce more severe AEs, resulting in discontinuation of 5ARI. (B) Progression of acute injury. A vicious cycle progresses from microvascular rarefaction to (2) oxidative stress injury and inflammation. (3) Inflammatory mediators may spread via the vascular network and lead to endothelial dysfunction,

elevating risk of inflammation and injury in other organs. (4) Discontinuation of 5ARI use may cause a rebound in angiogenic factors, potentially contributing to endothelial dysfunction. Fig. 1B main flow has been adapted from Fig. 1 of Textor \& Lerman (Semin Nephrol 2019;39:589-598) ) $^{62}$ with permission of the corresponding author. 

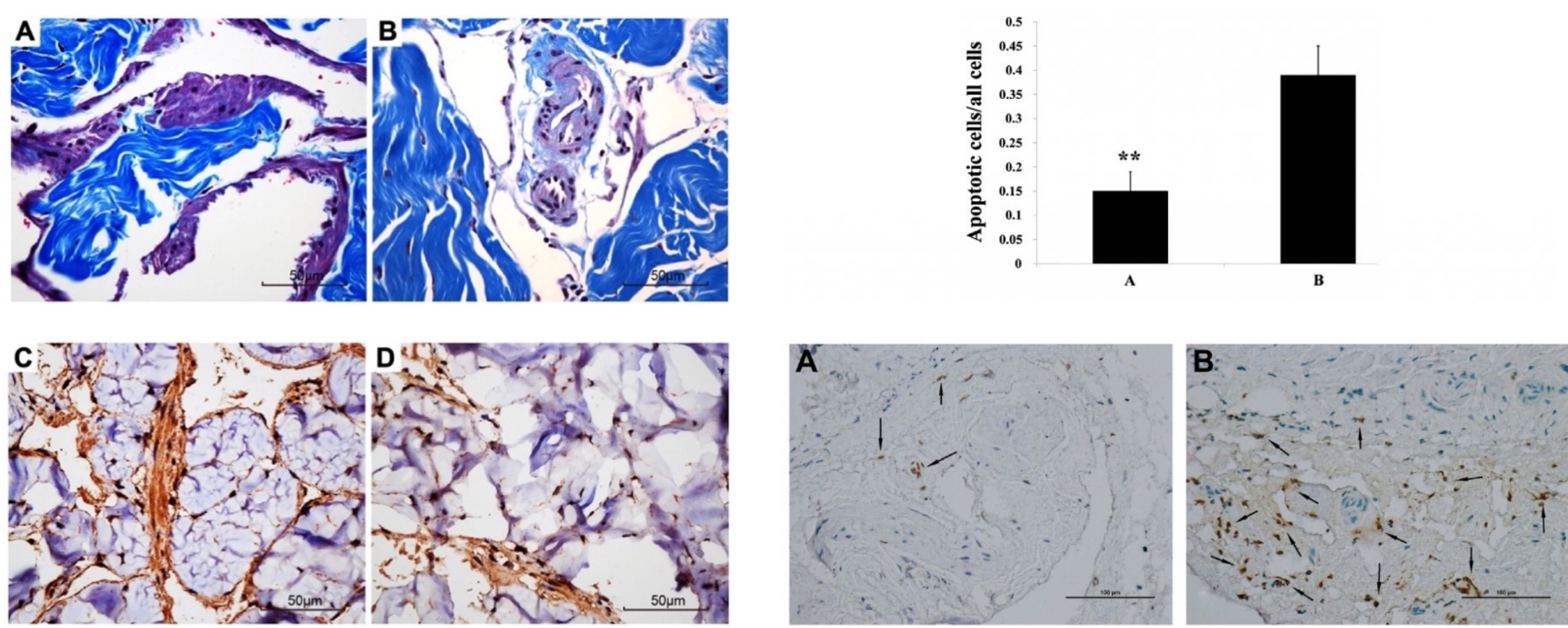

Fig. 2. Penile tissue changes in finasteride-treated rats vs. controls. (Top left) Histologic stain of tissue from corpus cavernosum. Purple $=$ smooth muscle; blue = connective tissue. (A) Sample from control group; (B) Sample from finasteride-treated group. Smooth muscle density in finasteride-treated group was reduced by $44.2 \% \pm 7.2 \%(P<.001)$ vs. controls. Authors wrote: "Substantial reductions in the smooth muscle content...and increases in connective tissue... in the corpus cavernosum were associated with 5ARI treatment." (Bottom left) Stain for endothelial nitric oxide synthase (eNOS) (brown) in corpus cavernosum. (C) Sample from control group; (D) Sample from finasteride-treated group. eNOS expression was reduced by $58.5 \%$ in finasteride-treated animals vs. controls. (Top right) Proportion of apoptotic cells in corpus cavernosum. (A) Control group; (B) Finasteride-treated group. The finasteride-treated group had "a much greater apoptotic index" compared to the control group. (Bottom right) Labeling assay of apoptosis in cavernosal tissue. (A) Control group; (B) Finasteride-treated group. Arrows indicate apoptotic cells with brown-stained nuclei.

Source: Figs. 2 \& 4 from Zhang et al (Urology 2013;82:743.e9-15). ${ }^{22}$ Reproduced with permission of the publisher. 

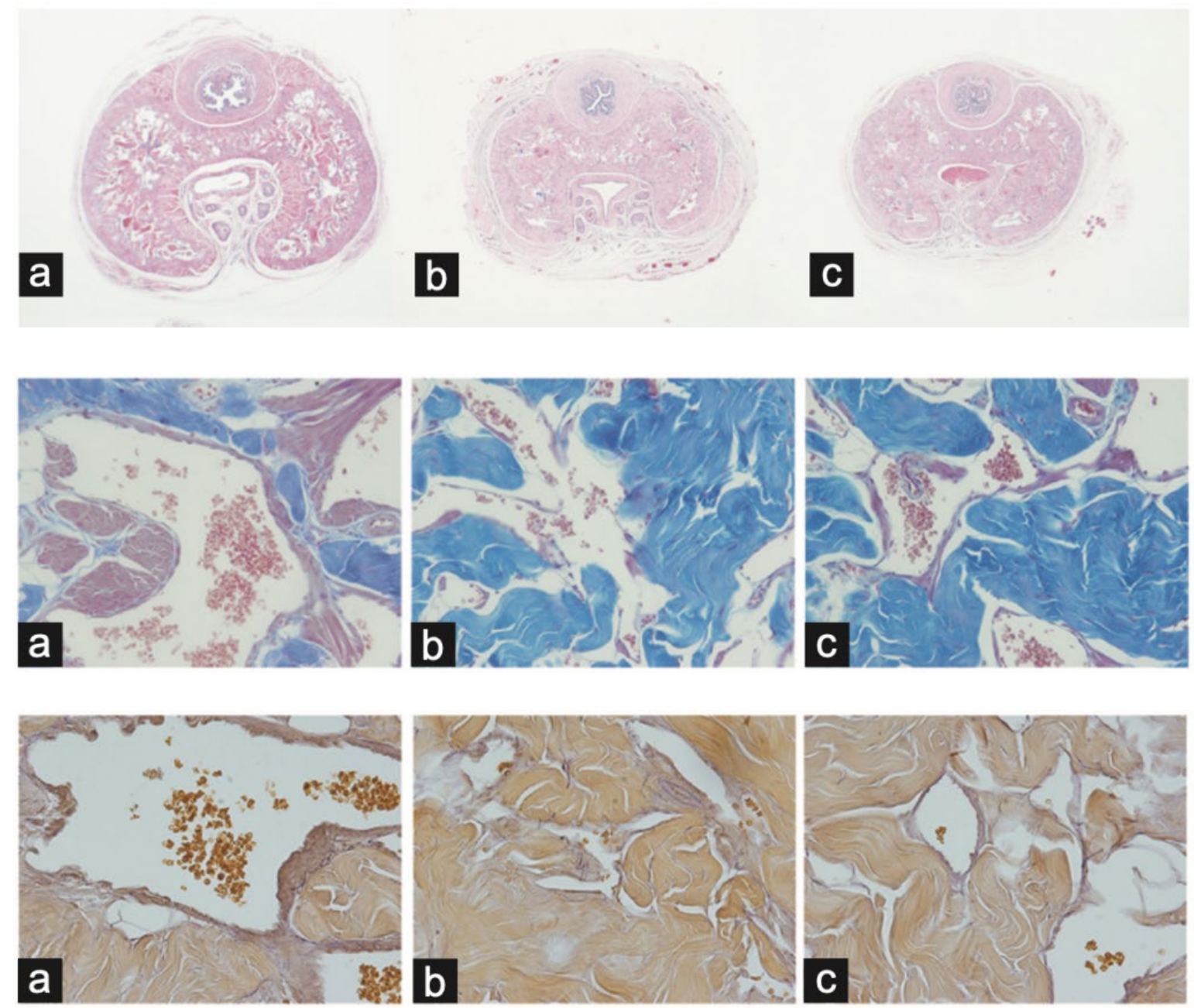

Fig. 3. Penile tissue changes in 5ARI-treated rats. (Top row) Penile cross-section at magnification $\times 20$. (b) Dutasteride and (c) Finasteride groups have reduced cross-sectional penile area when compared to (a) Control group. (Middle row) Smooth muscle in corpus cavernosum at $x 400$. Smooth muscle was reduced in (b) Dutasteride group compared to (a) Control group. (c) Finasteride group had no difference from controls in smooth muscle density or area (mean area was $55 \%$ lower in finasteride group without statistical significance). (Bottom row) In corpus cavernosum at x600, beige areas indicate elastic fibers. (b) Dutasteride and (c) Finasteride groups show increased amounts of elastic fibers compared to (a) controls.

Source: Figs. 1-3 from Da Silva MHA et al (Asian J Androl 2018;20:505-510). ${ }^{20}$ Reproduced with permission of the publisher. 
Control
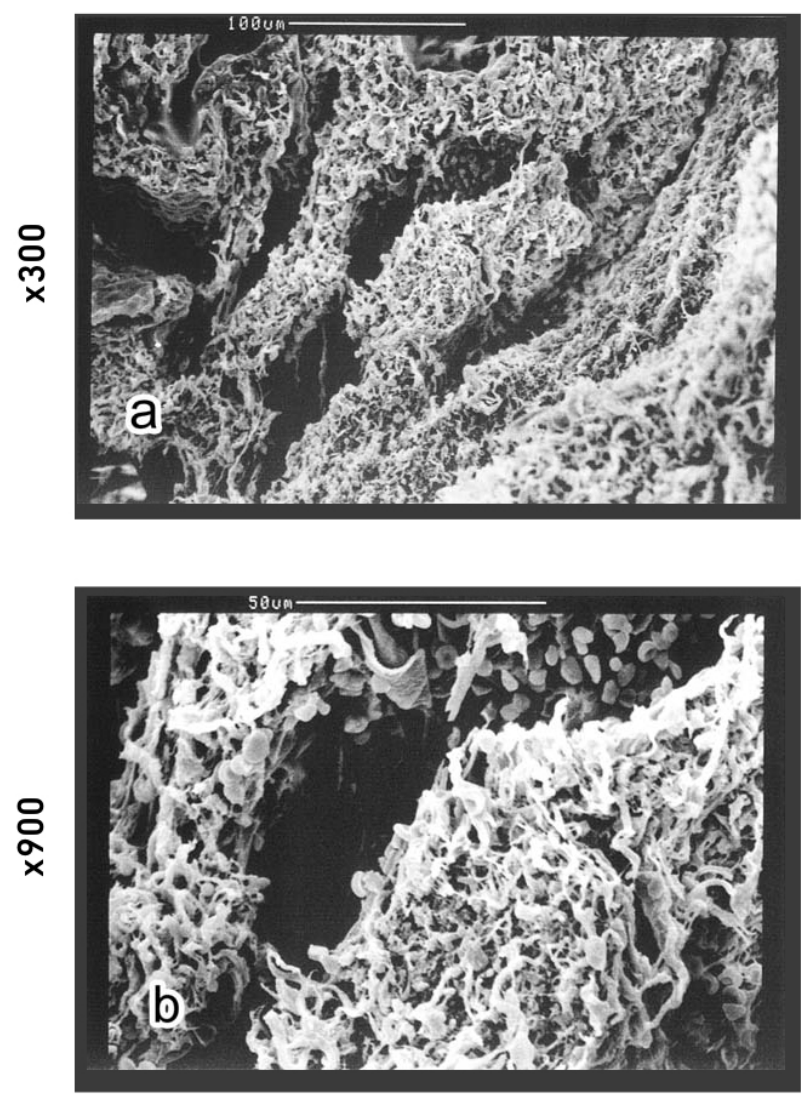

Finasteride-treated
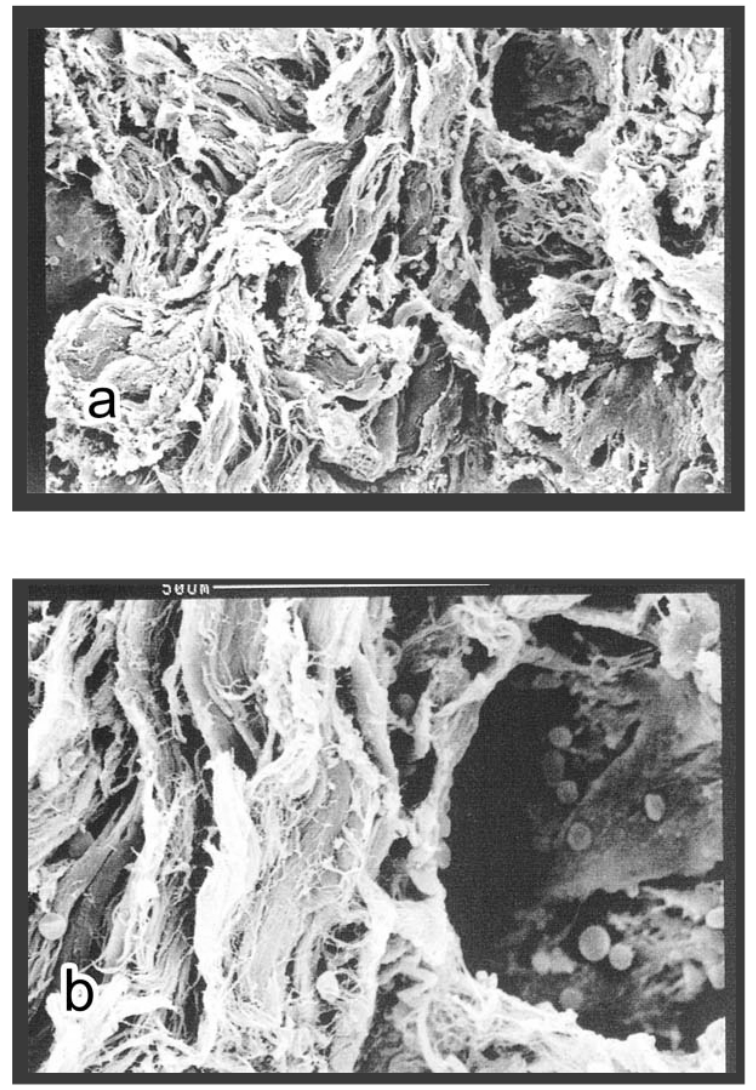

Fig. 4. Ultrastructure of corpus cavernosum in finasteride-treated rats vs. controls. (Left) Control rats. (Right) Finasteride-treated rats. Top images $\times 300$; bottom images $\times 900$. Shen et al. noted that in the corpus cavernosum of control rats, "the smooth muscle fibers in the trabeculae were rich and contained a few elastic and collagenous fibers. Structure of the sinusoids was perfect and clear." In finasteride-treated rats, "the corpus cavernosum... contained a considerable amount of thick and irregularly-arranged collagenous fibers, but the degree of fibrosis was not so marked as in [the castrated group - not shown] and the types of fibrosis were different between these two groups. The sinusoids were partially depressed, but the structure of the sinusoids was still retained [in finasteride-treated rats]."

Source: Figs. 4 \& 6 from Shen ZJ et al (Asian J Androl 2003;5:33-36). ${ }^{25}$ Reproduced with permission of the publisher. 


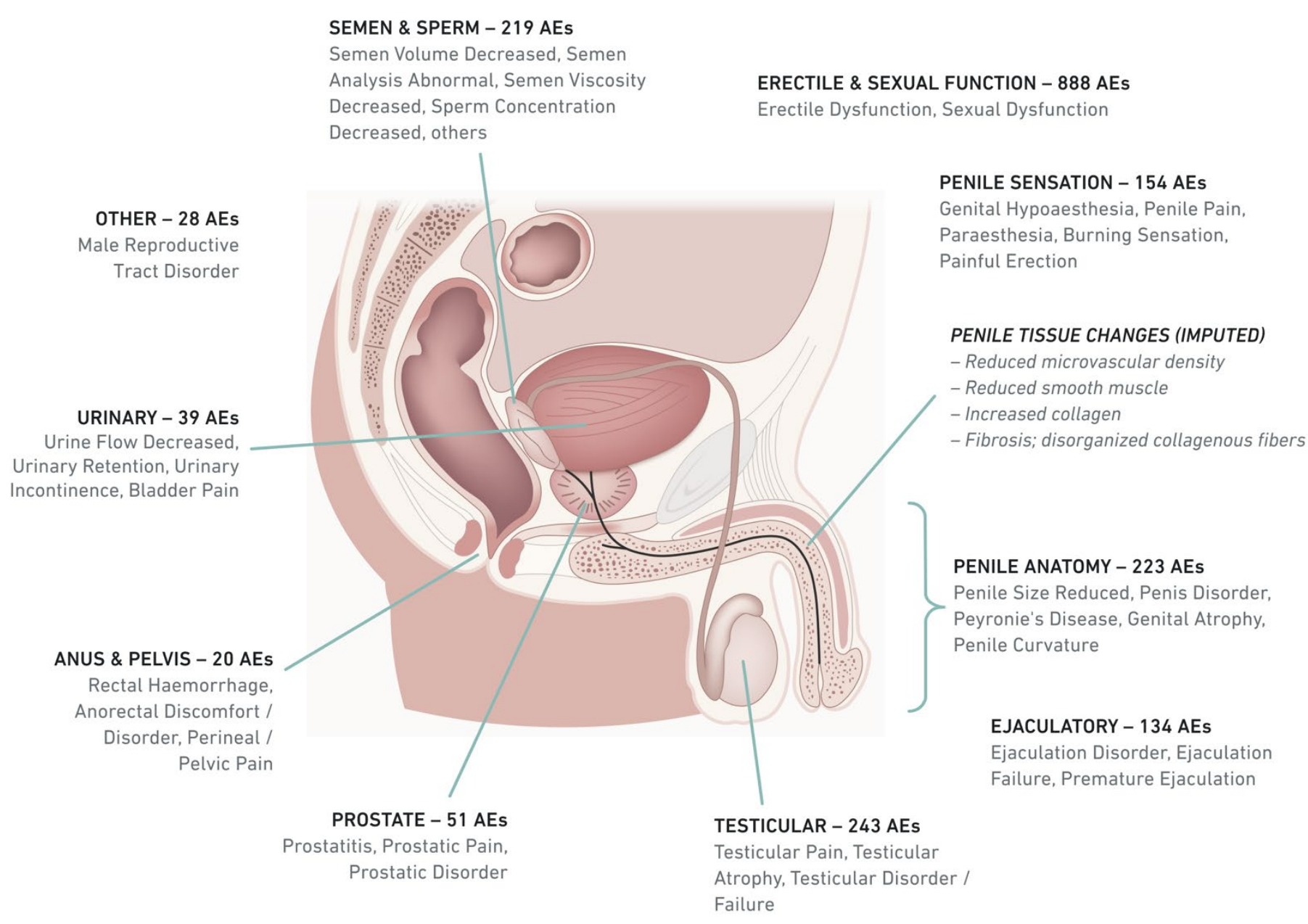

Fig. 5. Overview of adverse events of finasteride affecting male genitourinary system in men 18-40.

Filters (below) were applied to limit confounding factors. Captions show the most common AEs; see a complete list in Table 2B. Penile tissue changes (right, in italics) are imputed based on research discussed in text, with selected examples reproduced in Figures 2-4.

Source: FDA FAERS. Criteria: Received by FDA: 2000-2020; Sex: Male; Age: 18-40 years; Suspected Product: Finasteride only; Concomitant Products: None. 


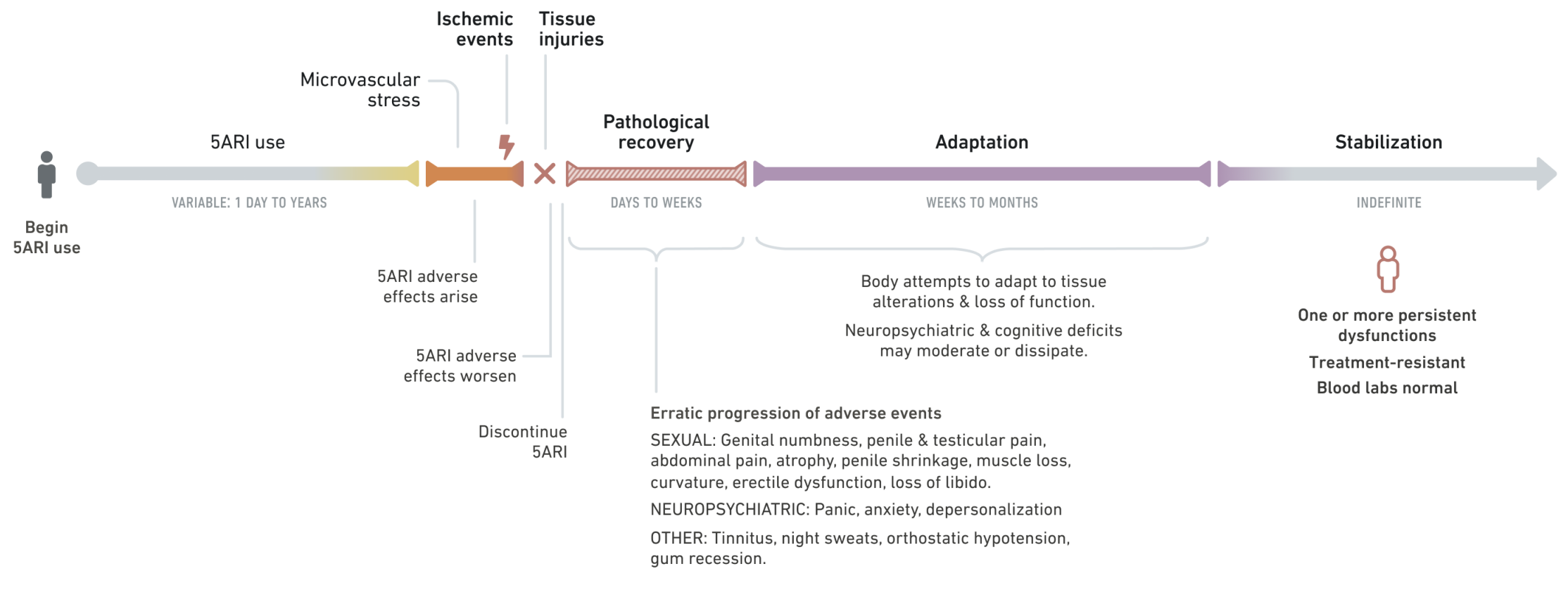

Fig. 6. Correspondence of PD-5ARI with phases of ischemia-reperfusion injury. In men who have developed PD-5ARI, a multiphase course is anecdotally common. Composition and severity of symptoms may change considerably over time (see also Figure 7). (Above timeline) The phased course of ischemiareperfusion injury show a suggestive correspondence with phases anecdotally associated with PD-5ARI. 


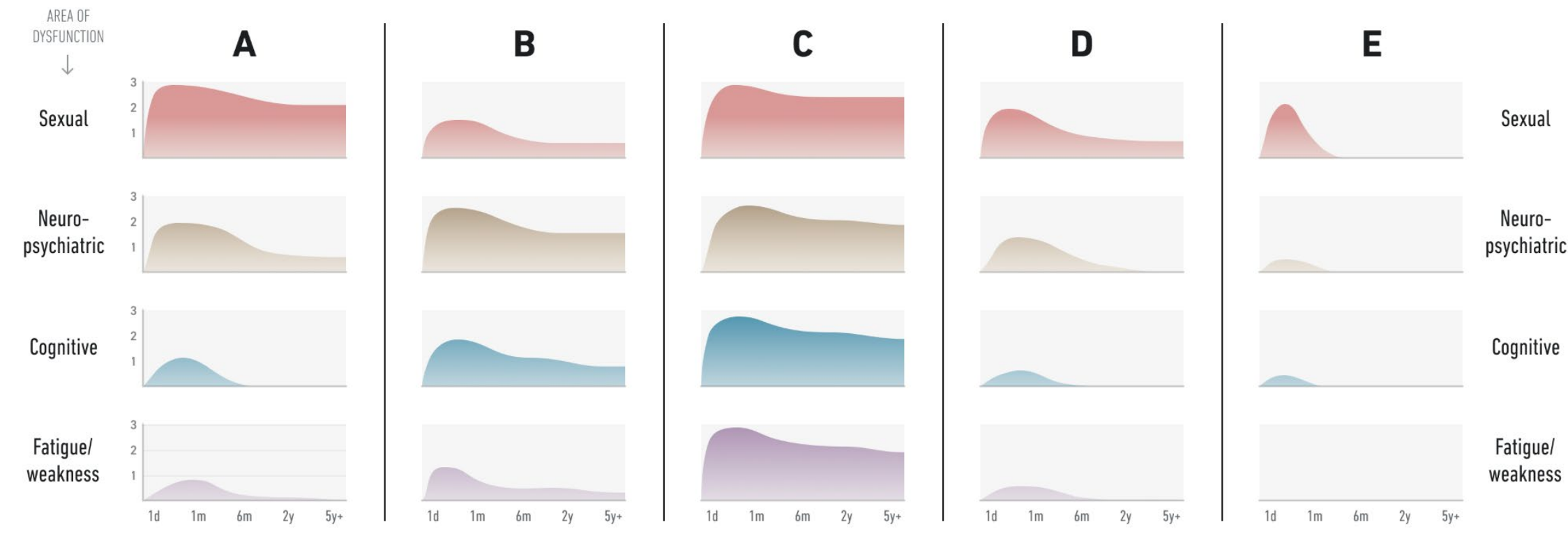

Fig. 7. Hypothetical cases illustrating variability of PD-5ARI. Columns A-E represent hypothetical cases. Rows refer to four areas of dysfunction: sexual, neuropsychiatric, cognitive and fatigue/weakness. Small charts represent severity of dysfunction over time: $Y$ axis: 1, low severity; 3 , high severity (more debilitating). X-axis: $d$, day; $m$, month; y, year. (A) Significant sexual and neuropsychiatric dysfunction in the first weeks and months. Over time, these dysfunctions moderate while cognitive dysfunction and energy deficits resolve. (B) More severe cognitive and neuropsychiatric dysfunction with relatively mild, but lasting, sexual dysfunction. (C) A severe case involving all four areas of dysfunction, which remain moderate to severe over the long term. (D) A mild case: relatively low-severity sexual dysfunction persists while other areas remit. (E) A "near-miss" case. Sexual, neuropsychiatric and cognitive symptoms arise after 5ARI discontinuation; however all dysfunctions resolve within weeks to months. 

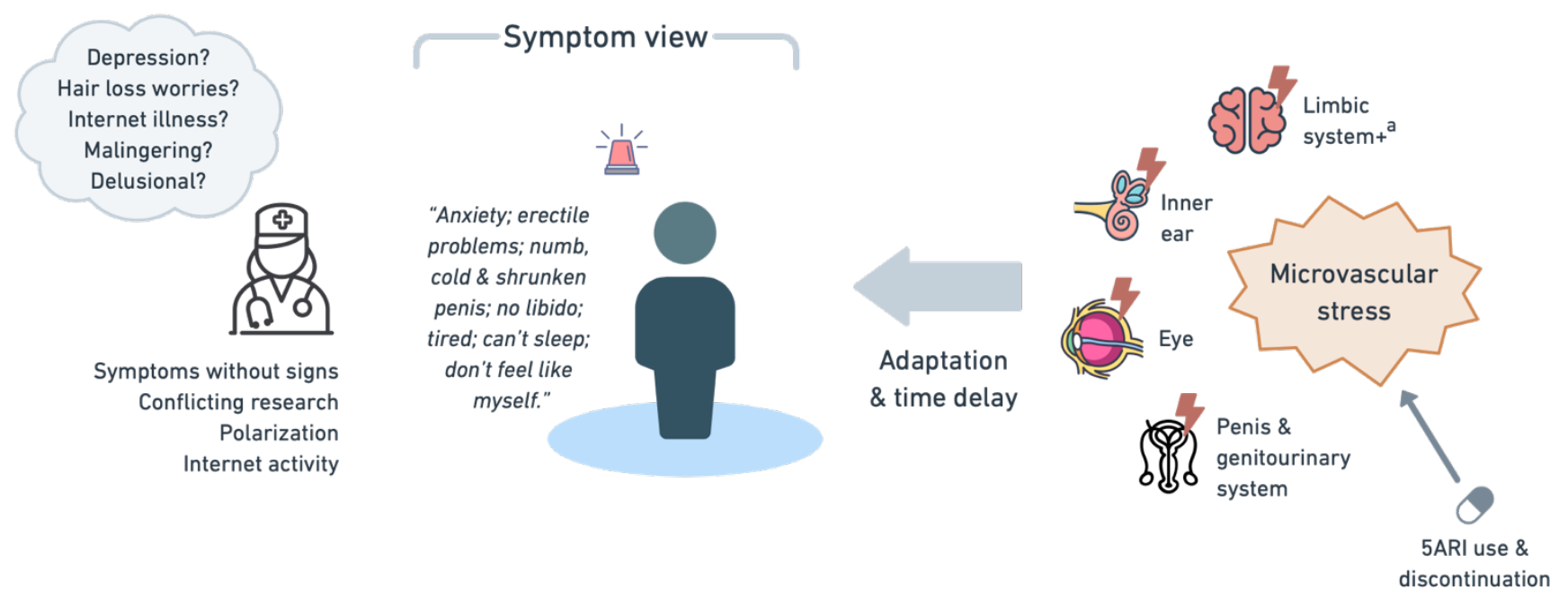

Fig. 8. Symptom view vs. system view of PD-5ARI. In the symptom view, doctors consult with patients, may find no diagnostic signs (e.g., lab tests normal) and conclude the condition is psychogenic. In the system view, symptoms would be interpreted as downstream consequences of prior injuries leading to organ dysfunction. This suggests a different clinical approach: seeking to identify and characterize tissue alterations and injuries rather than attempting to treat symptoms piecemeal.

${ }^{a}$ Hypothalamus, particularly medial preoptic area; hippocampus; thalamus; basal ganglia (see also Table 4). 
Epigenetic changes?

Microvascular stress



Fig. 9. Hypothetical downstream impact of hypoxic injury on epigenetics, neurosteroidogenesis and microbiome. Previous research has identified epigenetic and microbiome changes as consequences of ischemic injuries. Altered levels of neuroactive steroids could result from altered expression of enzymes due to tissue injury and inflammation. 
Table 1. 30 most frequently reported adverse events of finasteride by category

\begin{tabular}{|c|c|c|c|}
\hline Category & AE terms & AE count & $\%$ of all AEs \\
\hline $\begin{array}{l}\text { Sexual anatomy \& } \\
\text { function }\end{array}$ & $\begin{array}{l}\text { Erectile Dysfunction; Sexual Dysfunction; } \\
\text { Organic Sexual Dysfunction; Loss Of Libido; } \\
\text { Libido Decreased; Testicular Pain; Genital } \\
\text { Hypoaesthesiaa; Penile Size Reduced; Penis } \\
\text { Disorder; Ejaculation Disorder }\end{array}$ & 565 & $21.3 \%$ \\
\hline Neuropsychiatric & $\begin{array}{l}\text { Depression; Depressed Mood; Anxiety; } \\
\text { Suicidal Ideation; Feeling Abnormal; Panic } \\
\text { Attack; Anhedonia }\end{array}$ & 416 & $15.7 \%$ \\
\hline $\begin{array}{l}\text { Energy \& } \\
\text { musculoskeletal }\end{array}$ & Fatigue; Asthenia; Muscle Atrophy; Arthralgia & 144 & $5.4 \%$ \\
\hline $\begin{array}{l}\text { Memory, cognition \& } \\
\text { attention }\end{array}$ & $\begin{array}{l}\text { Amnesia; Cognitive Disorder; Disturbance In } \\
\text { Attention }\end{array}$ & 96 & $3.6 \%$ \\
\hline Sensory \& vestibular & Tinnitus; Dizziness; Vision Blurred & 76 & $2.9 \%$ \\
\hline Sleep & Insomnia & 71 & $2.7 \%$ \\
\hline General & Post 5-Alpha-Reductase Inhibitor Syndrome & 20 & $0.8 \%$ \\
\hline Endocrine & Gynaecomastia & 18 & $0.7 \%$ \\
\hline Subtotal & & 1,406 & $52.9 \%$ \\
\hline All AEs of finasteride & & 2,657 & $100.0 \%$ \\
\hline
\end{tabular}

Top 30 AEs reported to FDA FAERS for younger men taking finasteride for hair loss from 2018-2020, with filters (below) applied to reduce confounding factors. Filters yielded 376 cases (13.7\%) out of a total of 2,736 cases. AEs were disaggregated from cases and categorized (column 1). See Appendix for further background on the use of AE data.

Source: FDA Federal Adverse Events Reporting System Public Dashboard. Selection criteria: Received by FDA: 2018-2020; Sex: Male; Age: 18-40; Suspected product: Finasteride only; Reason for use: Androgenetic Alopecia and other hair loss conditions only, excluding Hair Transplant; Concomitant Products: None.

a Penile numbness. 
Table 2A. Genitourinary adverse events of finasteride and minoxidil by subsystem

\begin{tabular}{lrrrrrr}
\hline & \multicolumn{2}{c}{ Finasteride } & & \multicolumn{2}{c}{ Minoxidil } \\
\cline { 2 - 3 } \cline { 6 - 7 } Subsystem affected & AE count & $\%$ of total & & AE count & $\%$ of total \\
\hline Penis; erectile \& sexual function & 1,399 & $14.6 \%$ & & 39 & $1.3 \%$ \\
\hline Testicles & 243 & $2.5 \%$ & & 11 & $0.4 \%$ \\
\hline Semen and sperm & 219 & $2.3 \%$ & & 8 & $0.3 \%$ \\
\hline Urinary function, anus \& pelvis & 59 & $0.6 \%$ & & 1 & - \\
\hline Prostate & 51 & $0.5 \%$ & & - & - \\
\hline Global / ambiguous & 28 & $0.3 \%$ & & 3 & $0.1 \%$ \\
\hline Subtotal & 1,999 & $20.8 \%$ & & 62 & $2.0 \%$ \\
\hline Total drug AEs & 9,593 & $100 \%$ & & 3,031 & $100 \%$ \\
\hline
\end{tabular}

Filters (below) have been applied to minimize confounding factors. A pharmacovigilance signal analysis has not been performed; however, a comparison with minoxidil AEs may suggest drug-specific effects because both are used by a similar population as treatment for hair loss. Genitourinary AEs were $10.2 \mathrm{x}$ more common for finasteride (20.8\%) than for minoxidil (2.1\%).

Source: FDA FAERS. Selection criteria: Received by FDA: 2000-2020; Sex: Male; Age: 18-40; Suspected Product: Finasteride only or Minoxidil only; Concomitant Products: None. 
Table 2B. Genitourinary adverse events of finasteride

\begin{tabular}{|c|c|}
\hline Subsystem \& AE terms & Count \\
\hline Erectile \& sexual function & 888 \\
\hline Erectile Dysfunction; Organic Erectile Dysfunction & 686 \\
\hline Sexual Dysfunction; Male Sexual Dysfunction & 202 \\
\hline Penile anatomy & 223 \\
\hline $\begin{array}{l}\text { Penile Size Reduced; Penis Disorder; Peyronie's Disease; Male Genital Atrophy; } \\
\text { Genital Disorder; Penile Curvature; Genital Atrophy; Male Genital Examination } \\
\text { Abnormal }\end{array}$ & 223 \\
\hline Penile sensation & 154 \\
\hline Genital Hypoaesthesiaa & 84 \\
\hline $\begin{array}{l}\text { Penile Pain; Genital Pain; Genital Paraesthesia; Genital Burning Sensation; Genital } \\
\text { Discomfort; Painful Erection }\end{array}$ & 70 \\
\hline Ejaculatory function & 134 \\
\hline Ejaculation Disorder; Ejaculation Failure & 121 \\
\hline Premature Ejaculation & 13 \\
\hline Testicles & 243 \\
\hline Testicular Pain & 145 \\
\hline Testicular Atrophy & 50 \\
\hline Testicular Disorder; Testicular Failure; Seminoma; Other testicular AEs ${ }^{b}$ & 48 \\
\hline Sperm \& semen & 219 \\
\hline Semen Volume Decreased & 70 \\
\hline $\begin{array}{l}\text { Sperm concentration: Sperm Concentration Decreased; Azoospermia; Oligospermia; } \\
\text { Sperm Concentration Zero; Hypospermia; Sperm Concentration Abnormal }\end{array}$ & 43 \\
\hline $\begin{array}{l}\text { Semen consistency: Semen Viscosity Decreased; Semen Viscosity Increased; Semen } \\
\text { Viscosity Abnormal; Semen Liquefaction Abnormal; Semen Liquefaction }\end{array}$ & 34 \\
\hline Semen / Sperm Analysis Abnormal & 27 \\
\hline Semen Discolouration; Haematospermia & 19 \\
\hline $\begin{array}{l}\text { Sperm morphology: Spermatozoa Abnormal; Spermatozoa Morphology Abnormal; } \\
\text { Teratospermia; Spermatogenesis Abnormal }\end{array}$ & 16 \\
\hline $\begin{array}{l}\text { Sperm motility: Asthenospermia; Spermatozoa Progressive Motility Abnormal / } \\
\text { Decreased }\end{array}$ & 10 \\
\hline Urinary function, anus \& pelvis & 59 \\
\hline $\begin{array}{l}\text { Urine Flow Decreased; Urinary Retention; Urinary Incontinence; Bladder Pain; } \\
\text { Bladder Disorder; Perineal Pain; Anorectal Discomfort; Pelvic Pain; Other AEs }{ }^{c}\end{array}$ & 59 \\
\hline Prostate & 51 \\
\hline Prostatitis; Prostatic Pain; Prostatic Disorder; Other prostatic AEs ${ }^{d}$ & 51 \\
\hline Global / ambiguous & 28 \\
\hline Male Reproductive Tract Disorder; Urogenital Disorder; Genital Tract Inflammation & 28 \\
\hline Total genitourinary AEs & 1,999 \\
\hline
\end{tabular}

This table lists specific adverse events of finasteride which are summarized in Table $2 A$.

a Penile numbness.

besticular Mass; Testicular Torsion; Testicular Yolk Sac Tumour.

' Urinary: Gallbladder Disorder; Calculus Urinary; Bladder Discomfort; Bladder Dysfunction; Bladder Dysplasia; Bladder Neck Obstruction; Loss Of Bladder Sensation; Urine Output Decreased. Anus: Rectal Haemorrhage; Anal Haemorrhage; Anal Fissure; Anal Spasm; Rectal Spasm; Anorectal Disorder; Haematochezia. Pelvis: Pelvic Floor Dysfunction.

${ }^{d}$ Benign Prostatic Hyperplasia; Prostatomegaly; Prostate Tenderness; Carcinoid Tumour Of The Prostate 
Table 3. Vascular adverse events of finasteride and minoxidil

\begin{tabular}{lrrrrrr}
\hline & \multicolumn{2}{c}{ Finasteride } & & \multicolumn{2}{c}{ Minoxidil } \\
\cline { 2 - 3 } \cline { 6 - 7 } Subcategory & Count & $\%$ VAEs & & Count & $\%$ VAEs \\
\hline Circulation \& blood pressure & 54 & $59 \%$ & & 27 & $73 \%$ \\
\hline Occlusive events & $29^{\text {a }}$ & $32 \%$ & & 2 & $5 \%$ \\
\hline Hemorrhage & 9 & $9 \%$ & & $8^{\mathrm{b}}$ & $22 \%$ \\
\hline Subtotal & 92 & & & 37 & \\
\hline Total drug AEs & 9,593 & & & 3,031 & \\
\hline$\%$ of total drug AEs & $1.0 \%$ & & & $1.2 \%$ & \\
\hline
\end{tabular}

Occlusive AEs are those involving thrombosis, embolism, occlusion, ischemia or infarction. Within this set of vascular AEs, the proportion of occlusive events was $5.8 x$ greater for finasteride compared to minoxidil. If the ambiguous term Cerebral Disorder is included ( 5 occurrences for finasteride only), the proportion of occlusive events was $6.5 x$ greater for finasteride compared to minoxidil. See Supplement for a complete list of vascular AEs.

Source: FDA FAERS. Selection criteria: Received by FDA: 2000-2020; Sex: Male; Age: 18-40; Suspected Product: Finasteride only; Concomitant Products: None.

${ }^{a}$ Cerebrovascular Accident (4); Cerebral Venous Sinus Thrombosis (4); Retinal Vein Thrombosis (3); Venous Thrombosis (2); Superior Sagittal Sinus Thrombosis (2); Pulmonary Embolism (2); Deep Vein Thrombosis (2). One each of: Arterial Thrombosis; Basilar Artery Thrombosis; Brain Stem Ischaemia; Cerebellar Infarction; Cerebral Infarction; Cerebral Thrombosis; Cerebral Venous Thrombosis; Peripheral Arterial Occlusive Disease; Peripheral Embolism; Transient Ischaemic Attack. Excludes an ambiguous term, Cerebral Disorder (5).

${ }^{\mathrm{b}} 4$ AEs were Application Site Haemorrhage. 2 cases specified a topical product while the other 2 did not specify a product name. 
Table 4. Anatomical structures and systems implicated in PD-5ARI

\begin{tabular}{|c|c|c|}
\hline Dysfunction / symptom & Supporting structures \& systems & Disease analogues / references \\
\hline Sexual dysfunction & $\begin{array}{l}\text { Penis \& genitourinary system; medial } \\
\text { preoptic area and arousal circuits in } \\
\text { brain }\end{array}$ & $\begin{array}{l}\text { Penile fibrosis; Peyronie's disease; } \\
\text { penile injury; acute kidney injury to } \\
\text { chronic kidney disease transition }\end{array}$ \\
\hline $\begin{array}{l}\text { Neuropsychiatric } \\
\text { dysfunction }\end{array}$ & $\begin{array}{l}\text { Hypothalamus including medial } \\
\text { preoptic area; thalamus; ventral } \\
\text { striatum }\end{array}$ & Stroke; TIA; TBI \\
\hline Cognitive dysfunction & Striatum, thalamus \& hippocampus & Stroke; TIA; TBI \\
\hline $\begin{array}{l}\text { Musculoskeletal } \\
\text { dysfunction \& fatigue }\end{array}$ & $\begin{array}{l}\text { Bioenergetics \& microvascular } \\
\text { endothelium }\end{array}$ & Vasculitis; mitochondrial dysfunction \\
\hline $\begin{array}{l}\text { Vestibular \& auditory } \\
\text { dysfunction }\end{array}$ & $\begin{array}{l}\text { Thalamus; vestibulothalamic \& } \\
\text { auditory circuits }\end{array}$ & $\begin{array}{l}\text { Vestibulopathy; vestibular neuritis; } \\
\text { Ménière's Disease }\end{array}$ \\
\hline Eye conditions & Eye including optic nerve & Ischemic retinopathies \\
\hline Sleep dysfunction & $\begin{array}{l}\text { Sleep circuits in brain including } \\
\text { ventral tegmental area }\end{array}$ & Stroke; TIA; TBI \\
\hline Gum recession & Gum tissue & $\begin{array}{l}\text { Inflammatory processes leading to } \\
\text { periodontitis; systemic inflammation }\end{array}$ \\
\hline Systemic & $\begin{array}{l}\text { Vascular homeostasis; angiogenesis } \\
\text { and neoangiogenesis; inflammatory } \\
\text { response }\end{array}$ & $\begin{array}{l}\text { Systemic inflammation; endothelial } \\
\text { dysfunction; microvasculopathy; } \\
\text { systemic sclerosis; ischemia }\end{array}$ \\
\hline
\end{tabular}

Column 2 lists candidate structures and systems where injury might lead to dysfunctions in column 1. Disease analogues and references (column 3 ) are not proposed as equivalents, and may only overlap with dysfunctions of PD-5ARI in certain respects.

${ }^{a}$ E.g., joint pain, muscle weakness and muscle atrophy.

${ }^{b}$ E.g., tinnitus and orthostatic hypotension. 
Table 5. Comparison of stroke and PD-5ARI

\begin{tabular}{|c|c|c|}
\hline & Ischemic stroke & PD-5ARI (hypothesized) \\
\hline Etiology & Ischemia-reperfusion injury in brain & $\begin{array}{l}\text { Microvasculopathy or ischemia-reperfusion } \\
\text { injuries affecting multiple systems }\end{array}$ \\
\hline \multirow[t]{2}{*}{ Course } & $\begin{array}{l}\text { Critical vascular event } \rightarrow \text { Acute period } \rightarrow \\
\text { Tissue recovery process } \rightarrow \text { Stabilization }\end{array}$ & Parallel to stroke \\
\hline & Evolves over days, months \& years & \\
\hline \multirow{6}{*}{$\begin{array}{l}\text { Signs \& } \\
\text { symptoms }\end{array}$} & Variable symptom presentation \& severity & Variable symptom presentation \& severity \\
\hline & Limb paresthesia & Genital hypoesthesia \& paresthesia \\
\hline & Neuropathy & Loss of skin sensitivity \\
\hline & Brain tissue alterations & $\begin{array}{l}\text { Cerebrovascular events; penile tissue } \\
\text { alterations }\end{array}$ \\
\hline & Depression, anxiety \& apathy & Depression, anxiety \& anhedonia \\
\hline & Sleep disturbance & Sleep disturbance \\
\hline \multirow[t]{2}{*}{$\begin{array}{l}\text { Diagnostic } \\
\text { tests }\end{array}$} & CT scan; MRI; cerebral angiography & $\begin{array}{l}\text { Penile ultrasound imaging; MRI; pudendal } \\
\text { nerve evoked potentials }\end{array}$ \\
\hline & Neuropsychological tests & Sexual function questionnaires \\
\hline \multirow[t]{2}{*}{ Treatment } & Neurorehabilitation & $\begin{array}{l}\text { PDE5 inhibitors; other sexual medicine } \\
\text { therapies }\end{array}$ \\
\hline & Psychiatry; psychotherapy & Psychiatry; psychotherapy \\
\hline Prognosis & Variable outcomes & $\begin{array}{l}\text { Variable outcomes. Anecdotally, recovery of } \\
\text { sexual function seems uncommon while } \\
\text { moderation or resolution of neuropsychiatric \& } \\
\text { cognitive dysfunctions seems more common. }\end{array}$ \\
\hline \multirow[t]{3}{*}{ Impact on life } & Reduced motor and/or cognitive capacity & $\begin{array}{l}\text { Impaired sexual function affecting } \\
\text { relationships, sex and dating }\end{array}$ \\
\hline & Occupational \& social challenges & Occupational \& social challenges \\
\hline & May require major life changes & May require major life changes \\
\hline \multirow{4}{*}{$\begin{array}{l}\text { Alternative } \\
\text { diagnoses \& } \\
\text { misdiagnoses }\end{array}$} & TIA & Depression or other psychiatric diagnosis, \\
\hline & Stroke mimic & sometimes attributed to hair loss \\
\hline & Confusional state; dementia & Psychogenic erectile dysfunction \\
\hline & Depression & $\begin{array}{l}\text { Somatic symptom disorder; factitious disorder; } \\
\text { mass psychogenic illness }\end{array}$ \\
\hline
\end{tabular}

